IZA DP No. 5552

Age at Migration, Language and Fertility Patterns among Migrants to Canada

Alicia Adsera

Ana Ferrer

March 2011 


\title{
Age at Migration, Language and Fertility Patterns among Migrants to Canada
}

\author{
Alicia Adsera \\ Princeton University \\ and IZA \\ Ana Ferrer \\ University of Calgary
}

\section{Discussion Paper No. 5552 \\ March 2011}

\author{
IZA \\ P.O. Box 7240 \\ 53072 Bonn \\ Germany \\ Phone: +49-228-3894-0 \\ Fax: +49-228-3894-180 \\ E-mail: iza@iza.org
}

\begin{abstract}
Any opinions expressed here are those of the author(s) and not those of IZA. Research published in this series may include views on policy, but the institute itself takes no institutional policy positions.

The Institute for the Study of Labor (IZA) in Bonn is a local and virtual international research center and a place of communication between science, politics and business. IZA is an independent nonprofit organization supported by Deutsche Post Foundation. The center is associated with the University of Bonn and offers a stimulating research environment through its international network, workshops and conferences, data service, project support, research visits and doctoral program. IZA engages in (i) original and internationally competitive research in all fields of labor economics, (ii) development of policy concepts, and (iii) dissemination of research results and concepts to the interested public.
\end{abstract}

IZA Discussion Papers often represent preliminary work and are circulated to encourage discussion. Citation of such a paper should account for its provisional character. A revised version may be available directly from the author. 


\section{ABSTRACT \\ Age at Migration, Language and Fertility Patterns among Migrants to Canada*}

This paper explores the fertility decisions of Canadian immigrants using a 20 percent sample of the Canadian Census of Population for the years 1991 through 2006. We focus on those individuals that migrated as children and on their age at arrival to assess their process of assimilation in terms of fertility. Our analysis does not show any sharp discontinuity in fertility by age at migration as sometimes observed on education or labor market outcomes. Instead, there is an inverted $U$ shape relationship between age of migration and immigrant fertility, with those migrating in their late teens having the highest fertility rates when compared to natives. This pattern appears among migrants from all origins - although their fertility levels differ. Results suggests that language acquisition is not a key mechanism through which age at immigration affects fertility - fertility behavior of immigrants with an official mother tongue also differs from that of natives. Rather fertility assimilation seems to be associated with education decisions. College graduates arriving to Canada anytime before adulthood behave as their native peers.

JEL Classification: J13, J15, J61

Keywords: fertility, migration, age at migration, language

Corresponding author:

Alicia Adsera

Woodrow Wilson School

Princeton University

347 Wallace Hall

Princeton NJ 08544

USA

E-mail: adsera@princeton.edu

\footnotetext{
* We thank seminar participants at PAA, European Population Conference (Vienna), Instituto de Economía, Geografía y Demografía (CSIC, Madrid), Vienna Institute of Demography, Princeton University, INED (Paris), Universidad de Alicante Tilburg University, and Université de Toulouse for their comments. We are grateful for the support of the analysts at Prairie Regional Research Data Centre at the University of Calgary.
} 


\section{NON-TECHNICAL SUMMARY}

This paper examines fertility patterns Canadian immigrants. We use the confidential files of the Canadian Census of Population for the years 1991 through 2006. We focus on those migrating as children (before age 18) and use "age at immigration" to measure the extent of their assimilation. Our analysis shows fertility assimilation is a relatively smooth process, with fertility increasing gradually with age at immigration. We do not find sharp discontinuities in the level of fertility for individuals arriving after certain ages as sometimes observed when analyzing education or labor market outcomes. Rather, there is a somewhat inverted $U$ shape relationship between age of migration and immigrant fertility, with those migrating in their late teens having the highest fertility rates when compared to the Canadian born. This pattern of assimilation is not specific to individuals migrating from a particular geographic area, but it is present across all immigrants from very different broad cultural backgrounds (although their fertility levels differ).

We explore possible channels through which the age at arrival matters. We use the mother tongue of the immigrant to proxy the initial hurdles an individual faced to learn the language combined with the particular stage in their childhood at which he arrived into Canada. Our analysis suggests that language acquisition does not seem to be the key mechanism through which age at immigration affects fertility - fertility behaviour of immigrants with an official mother tongue also differs from that of natives and increases smoothly with age at migration. Rather fertility assimilation seems to be associated with education decisions. The fertility patterns of those attaining post-secondary education are similar to natives regardless of age at migration. 


\section{Introduction}

During recent years, low fertility rates, particularly in Europe, and shrinking working-age cohorts have led to a massive and diverse inflow of immigrants into OECD countries. As immigrant fertility rates in many source countries are still higher than those of native born, the extent of the fertility adjustment of immigrants plays a role in gauging their contribution to the future demographic structure of recipient countries. This in turn is relevant in planning fiscal policy and in assessing the sustainability of generous welfare states burdened by increasing agedependency ratios and by demographic pressures on social services as the baby-boom generation retires (Belanger et al. 2005; Coleman 2006; United Nations 2000). Yet, as Sobotka (2008) notes, even if immigrants contribute substantially to the total number of births across European countries, their 'net effect' on the period total fertility remains relatively small, typically between 0.05 and 0.10 in absolute terms.

In addition the importance of understanding the fertility behavior of immigrant households goes beyond pure demographic projections. Childbearing decisions impact the well-being of households in multiple dimensions and are related to education and labor market participation choices. Specifically, the analysis of immigrant fertility differentials helps to understand the socio-economic integration of immigrant women, and the changing shape of family structure in immigrant recipient countries. Human capital investment and labor market behavior of female immigrants have long reaching consequences in altering traditional gender roles within immigrant households. Smaller family sizes may increase the investment per child (more quality over quantity) and improve the outcomes of the next generation. In addition reduced fertility may increase the labor market opportunities of immigrant women and add to the welfare of the family through higher income.

In this paper we study fertility behavior of first generation immigrant women in Canada, one of the OECD countries with the largest share of foreign born, and compare it to the childbearing patterns of native women. Between 1990 and 2000, the annual number of births in Canada declined by $19 \%$. The reduction in births is partly attributable to an aging population, with large cohorts of the baby-boom gradually moving out of their fertile years, and partly attributable to changes in the reproductive behavior of the Canadian population. The total fertility rate (TFR) has been falling steadily for nearly a decade, and was in the year 2000 13\% lower than in 1990. Although variations in total fertility rate may only reflect year-to-year changes in conditions 
affecting childbearing decisions and tempo-effects (young cohorts postponing births to older ages), the reduction in fertility among current cohorts during their earlier years seems too large to be compensated by higher fertility later in life. ${ }^{1}$

These demographic trends were partly behind the current immigration policy in Canada whose aim is to maintain labor force growth (Green and Green, 1994). As a result of this policy, the immigrant population, as a percentage of total Canadian population, has almost doubled between 1980 and 2006. Estimates from the 2006 Canadian Census indicate that 20\% of Canada's population is foreign born and that another $13 \%$ are the children of foreign born parents or second generation Canadians. The demographic contribution of immigrants is not, however, limited to the direct effect on population counts. Although the fertility of foreign-born Canadian women was formerly lower than that of women born in Canada, among recent arrival cohorts it is higher. ${ }^{2}$ Overall, the fertility rates of both groups have diminished since the 1970s, but the fertility of Canadian born women has fallen by $35 \%$, whereas that of foreign born women fell by only $12 \%$ between 1976 and 2000. This is partly attributed to the change in the composition of source countries among immigrants. The most recent immigrants tend to come from countries with higher fertility (South Asia and Latino America) and they seem to retain, at least for a time, some of the fertility behavior observed in their country of origin (Belanger and Gilbert 2003).

We use the confidential files of the Canadian Census of Population for the years 1991 through 2006. We focus on those migrating before adulthood to assess the process of assimilation in terms of fertility and use age at immigration to measure the extent of assimilation. Our analysis shows fertility assimilation as a relatively smooth process, with fertility increasing gradually with age at immigration. We do not find sharp discontinuities in this process as sometimes observed when analyzing education or labor market outcomes. Rather, there is an inverted $U$ shape relationship between age of migration and immigrant fertility, with those migrating in their late teens having the highest fertility rates when compared to the Canadian

\footnotetext{
${ }^{1}$ A look at the completed fertility of different cohorts, which measures the actual number of children born to women at the end of their fertile years, is necessary to obtain the overall picture of fertility trends, During the baby-boom, the TFR greatly exceeded the completed fertility of the corresponding cohorts because it was, in part, swelled by the acceleration of the tempo. By contrast, since the late 1960s, the completed fertility rate of the cohorts has been greater than the corresponding TFR

${ }^{2}$ The fertility of immigrant women has overtaken that of Canadian born women since the early 1980s
} 
born. This pattern of assimilation is present in immigrants from different broad cultural backgrounds, although at different paces.

Further we explore possible channels though which the age at arrival matters. Previous research has focused on the differences in language proficiency at destination by country origin (or mother tongue) and the age at arrival (Chiswick 1991; Chiswick and Miller 2001; Espenshade and Fu 1997; Stevens 1999; Bleakley and Chin, 2004; Akresh 2007). We use the mother tongue of the immigrant to proxy the initial hurdles an individual faced to learn the language combined with the particular stage in their childhood at which he arrived into Canada. However, our analysis suggests that language acquisition does not seem to be the key mechanism though which age at immigration affects fertility - fertility behaviour of immigrants with an official mother tongue also differs from that of natives and increases smoothly with age at migration. Rather fertility assimilation seems to be associated with education decisions. The fertility patterns of those attaining post-secondary education are similar to natives regardless of age at migration.

The next section of the paper briefly reviews recent stylized findings on fertility behavior and assimilation of immigrants in developed countries that inform our analysis. We then describe the data employed and the empirical strategy followed in the analysis. The following section focuses on the childbearing patterns of migrants who arrived in the country before adulthood. We show their estimated patterns of fertility by age at migration as compared to those of the Canadian born. We explore different channels through which age at migration is likely related to fertility behavior, mainly language acquisition and educational attainment. We conclude with some general comments about the findings and future research.

\section{Fertility Behavior of Immigrants}

Fertility behavior likely plays an important role in many dimensions of immigrant wellbeing, as childbearing shapes the socio-economic assimilation and mobility of immigrant women. Individual investments in human capital usually require postponement of fertility, and employment opportunities and career advancement are generally difficult for women with a large number of children. ${ }^{3}$ Therefore, high (and early) fertility may hinder the socio-economic integration of immigrant women, perpetuating more traditional gender roles within immigrant

\footnotetext{
${ }^{3}$ Adsera (2004) shows the connection between labor market institutions and fertility using evidence from Europe.
} 
households. Improved economic opportunities in Canada compared to those in the country of origin and their interaction with Canadian-born may, on the other hand, affect the fertility preferences of immigrants. Alternatively, even if childbearing preferences remain the same, the new environment that immigrants face in Canada, both in terms of opportunities and of costs, may alter their ultimate fertility decision. Immigrant women may face better labor market prospects than in their countries of origin and decide to reduce/postpone fertility in order to work. Also, in the absence of informal child care provided by relatives, they may find formal daycare expensive and, as a result, decide to trade off children for work (Galor and Weil, 1996). Furthermore, given the trade-offs faced in terms of time and resources within households, a choice of more children over more resources devoted to the rearing of each child may affect the well-being of the second generation of immigrants. ${ }^{4}$ For instance, Blau et al. (2008) find that in the United States second-generation women's schooling levels are negatively affected by the average fertility of immigrants of their parents' descent.

Different models in the literature of fertility adjustment try to account for the fertility experiences of adult immigrants. The assimilation model suggests that couples migrating from a country with relatively high fertility rates will initially follow their own country's fertility patterns and will only gradually adjust to the fertility rates of the host country. In the short run, however, fertility may follow the disruption model, which postulates an initial drop in couples' fertility around the time of migration (explained in part by moving costs) and a fertility rebound later on (Blau 1992; Kahn 1994). The two models can be combined, and it may be possible to observe an initial drop in fertility at the time of immigration, followed by a subsequent rise in fertility bypassing that of natives and a gradual decline to converge to the host country levels.

Empirical results on the patterns of immigrant fertility are mixed. Blau's influential study (1992) seems to support the disruption model with a short run fertility adjustment of immigrants in the United States. Current research is more focused on long run fertility adjustments. Among others, Parrado and Morgan (2008) find compelling empirical evidence of fertility assimilation for Hispanic women in the United States. Anderson (2004) shows large differences in fertility levels between different groups of migrants to Sweden. Georgiadis and Manning (2011) explore the relatively slower fertility assimilation of Pakistanis and Bangladeshis as compared to Chinese, Indians and Black Caribbean in Britain, among other immigrant outcomes.

\footnotetext{
${ }^{4}$ The trade-off between quality and quantity of children is outlined in Becker (1981).
} 
In Canada, fertility studies show that up to 1980 Canadian immigrants had lower fertility rates than the Canadian born (Kalbach 1970), but that trend has since reversed. Ng and Nault, (1997), and Ram and George (1990) find evidence of short lived fertility disruption upon immigration and quick convergence to domestic born fertility levels along with socio-economic assimilation. A study by Belanger and Gilbert (2003) suggests that the increase in the share of Canadian immigrants from areas with traditionally high fertility rates such as the Middle East, Southern Asia and Latin America is likely responsible for the change in fertility patterns. Before 1980, the majority of immigrants came from the United States or Europe (41\%). By 2006 this fraction was down to $19 \%$ of recent arrivals (within the last five years). Currently, immigration from Asia constitutes 58\% of recent arrivals versus 34\% of all those who arrived before 1980 , and twice as many recent newcomers are from Africa as there were before 1980. Both the increase in immigration and its compositional change have led to an extensive literature documenting the economic performance of recent immigrants and how well they assimilate into Canadian labour markets. ${ }^{5}$ Surprisingly, few of these studies consider fertility assimilation.

The traditional models of fertility adjustment described above apply generally to adult immigrants. It is less clear what fertility patterns to expect from those who immigrate as children. Immigrant children could either behave like first generation immigrants, like the native born, or somewhere in between. As suggested in Fernandez and Fogli (2009), the assimilation process may take more than one generation to accomplish. Even those arriving to the host country at very young ages may be influenced by their parents' cultural expectations and exhibit fertility patterns closer to those of their ancestors than to the native born. On the other hand, if child immigrants assimilate in the host country relatively fast through schools and peer groups, they will adopt the fertility patterns of the native born. In this regard, the literature on immigrant assimilation has long recognized age at immigration as a decisive variable for understanding the process of assimilation of immigrants in many socio-economic dimensions (Chiswick, 1991).

In our analysis we will focus on the fertility assimilation of immigrants arriving before adulthood. Early arrival affords the person more time in the host country and increases the likelihood that the young migrant attends school and understands early in life the rules and institutions governing the socio-economic life of the receiving country. In addition, age at

\footnotetext{
${ }^{5}$ See Aydemar and Skuterud (2005) and Ferrer, Green, and Riddell (2006) and Picot et al. (2007) among others.
} 
immigration may also matter if there are critical ages at which individuals learn a particular behavior or skills that are crucial for assimilation (Bleakley and Chin, 2010 Schaafsma and Sweetman, 2001). The later mechanism suggests that we may observe sharp discontinuities in fertility assimilation depending on age at arrival. In the analysis below we are interested in assessing the importance of age at immigration for fertility behaviour and how it helps us to understand the process of fertility assimilation of immigrants.

\section{Data and Empirical Approach}

Both the number of children women have and the timing of childbearing over their fertile life are important dimensions of the analysis of fertility behaviour. In this paper we focus on the total number of children born to women aged 16 to 45 , conditional on their migration status as well as on a set of additional independent variables.

Ordinary least squares is not an appropriate method to estimate variation in event count dependent variables such as the number of children. Event count models, such as Poisson, measure how often an event - in this case, having a child - occurs over a given time interval. We use the following Poisson regression model to estimate fertility.

$$
F_{i}=e^{\beta I i+\gamma X i}+\varepsilon_{i}
$$

where $F$ is the measure of fertility of female $i$ (in our case, total number of children), $I$ is an immigrant indicator, $X$ is a vector of individual characteristics, including age, presence of additional members in the household, geographic location, socio-economic status of the household, or cultural/religious background, and $\varepsilon$ is the error term. Since we observe respondents of different ages, we control for their exposure time to fertility (defined as age minus 15 years) in our models. In general, coefficients from non-linear models have no immediate interpretation. For this reason we report in the tables the incident rate ratios (IRR). In the most parsimonious model, we are interested in comparing the predicted fertility rate (or fertility incidence) between two observations that differ only in that the variable $I_{i}$ takes on a value of 1 for immigrants and 0 for the Canadian born. The ratio of these two incidence rates is given by

$$
\operatorname{IRR}\left(I_{i}\right)=\frac{E\left(F_{i} \mid I_{i}=1\right)=\exp (\hat{\gamma} X+\hat{\beta}(1))}{E\left(F_{i} \mid I_{i}=0\right)=\exp (\hat{\gamma} X+\hat{\beta}(0))}=\exp (\hat{\beta})
$$


Equation (2) states the effect of a one unit change in the independent variable on the relative incidence rate of fertility. In the case of indicator variables such as our immigrant indicator $I$, the relative incidence rate can also be interpreted as the fertility rate for immigrants relative to the Canadian born. ${ }^{6}$

The data in the paper comes from the confidential files of the Canadian Census of Population (20\% sample) for the years 1991, 1996, 2001, and 2006. Confidential census data have the advantage of providing large samples necessary to perform robustness analysis of the estimates. They also include more detailed information on individuals, as well as a richer categorization of relationships among members of the household than it is regularly available. With this detailed information, we are able to link individuals within the household and to compute the number of children of each woman living in a household. From each census year, we select all women between 16 and 45 years of age, except for aboriginal individuals, and gather information on age, education, marital status, number of children (in the 1991 Census), number of children living in the household, province of residence, religion (1991 and 2001 Census) and immigrant status. In addition, for immigrant women we collect their year of immigration, age at immigration and country of birth. ${ }^{7}$ To reduce computing time to a reasonable length, each year we select all immigrants plus a 20 percent random sample of domestic born individuals and weight observations accordingly. The four censuses are then pooled, resulting in approximately $1,800,000$ observations.

In general, vital statistics are the most accurate source of information for fertility records in developed countries. However, since they only contain little additional information about the individual and the household, they are inadequate for an in-depth analysis of fertility behavior. For this reason, an alternative method is generally used to indirectly estimate fertility from survey information such as Census data, which typically reports the number of children living in the household. The method, known as the "own children method", exploits the fact that the vast majority of young children live with their mother at the time of the census. Since the date of birth of both mother and children is known, it is easy to reconstruct each woman's fertility history.

\footnotetext{
${ }^{6}$ Similarly, in the case of a continuous variable such as age, the IRR could be interpreted as the increase in fertility rate when age increases by one year.

${ }^{7}$ We have grouped the information for country of origin into 20 relatively homogenous groups. These are listed in Table B in the appendix.
} 
In line with these studies, we use the number of children living in the household as our measure of fertility in the analysis that follows. To the extent that some children may not live with their mothers, our dependent variable may be measured with some error. ${ }^{8}$ To reduce this problem, we restrict our sample to relatively young women (up to 45 years of age) whose children are more likely to live at home. Still, there are several caveats to the measure. First, the census questionnaire asks respondents to include children in joint custody who live most of the time in a household as household members. Therefore, we will miss all the children who are living only with their father. To the extent that young children are far more likely to live with their mothers, even after marriage disruption, this will not be too important. ${ }^{9}$ Second, it may be difficult to properly capture the very early childbearing of older women in the sample as some of their children may have already left home. That should be a concern particularly if the departure of children from the household in their late teens or early adulthood (e.g., attending college far from home, earlier marriage or cohabitation) occurs at a differential rate between immigrants and the Canadian born.

To assess the importance of the potential bias introduced by our dependent variable, we undertake three types of robustness exercises. First, we use the total number of children ever born, available in the 1991 census, to re-estimate the models and compare the results with those obtained for the 1991 Census using our fertility measure. Second, we further restrict the sample to women up to age 40 . This reduces the likelihood that some children have already left home but it misses late childbearing, which may in turn be differentially important among groups (e.g., according to education, country of origin, etc). However, Vezina and Turcotte (2009), after comparing data from the Canada Census and from the General Social Survey, note that there is no appreciable bias in the characteristics of the fraction of women aged 40 to 44 who have a child aged five or over based on whether some of the children live with them or not. Third, we re-estimate the models restricting the age of the children included in our fertility measure to those 18 and under. Differences in the results when using this definition of the dependent

\footnotetext{
${ }^{8}$ Belanger and Gilbert (2003) show that estimated fertility differentials for immigrants and domestic born individuals for the period 1996-2001 using both methods are not very sizeable - with a downward bias of the census for women younger than 30 and an upward bias for those aged beyond 30 .

${ }^{9}$ In some instances, several women live in a household with children and we cannot be certain of which one is the mother of the children. This happens, for example, when the children are reported as grandchildren of the head of the household and there is more than one daughter of the head of the household living in the household. This is not, however, a common occurrence.
} 
variable will indicate that the bias introduced by the own children method is important. The overall pattern of the results and the estimated coefficients are robust across these different samples and specifications. These are available upon request.

(Table 1 here)

Table 1 shows summary statistics of the main variables separately for Canadian born and for immigrants. The first two columns correspond to the whole sample over the 1991, 1996, 2001, and 2006 censuses. In order to provide a sense of the temporal variation in the data over the sample period, the table also includes statistics for 1991 and 2006 separately. On average, immigrants have more children than the Canadian born and for both groups the average number of children diminishes by approximately 15 percent between 1991 and 2006. Immigrants in the sample have higher educational attainment and are generally older than the Canadian born. The age difference may account for part of the gap in mean fertility observed between both groups. More immigrants are married -- or living together under common law (CL) -- than Canadian born. Between 1991 and 2006, the percentage of married/CL individuals fell for both groups (around 9 points for Canadian born and 4 points for immigrants), while the fraction of single individuals increased by a similar magnitude in each case. Finally, fewer immigrants with children live in households with additional family members besides their spouse than Canadian born (3 percent versus 8 percent, respectively). The average immigrant has been in Canada about 13.4 years and arrived at the age of 19.5. Around 50 percent of the individuals arrived in Canada as adults, past the age of upper secondary schooling. Figure 1 presents the distribution of ages at migration for the sample. After a small spike for toddlers, the fraction of entrants remains more or less flat until reaching its peak between the ages of 20 and $30 .{ }^{10}$ The fraction of recent immigrants over the whole pool has increased in the latest Censuses and current immigrants arrive at a slightly older age than in the past. Further, immigrants are increasingly arriving from countries in Asia and Africa rather than from Europe. Consequently, the fraction of immigrants with a non-official mother tongue, or that of immigrants using a non-official language at home has steadily increased over the period 1991-2006. These trends, which are likely to have an

\footnotetext{
${ }^{10}$ The distribution varies substantially by country of origin. If immigrants from Europe or the United States are removed from the sample, the distribution of immigrants by age at immigration resembles more a normal distribution centered at the early twenties.
} 
impact on fertility behaviour, are well documented in the Canadian literature of immigration (Picot and Sweetman, 2005).

(Figure 1 here)

Table 2 shows the mean number of children living at home by Census year and selected characteristics for women aged 16 to 45 in each census. The mean is higher among immigrants than Canadian born, although both groups display a similar diminishing trend over time. We show mean number of children by "years since migration” for each Census year to offer a rough idea of how immigrant fertility patterns evolve over time. In 1991, recent immigrants (those with less than five years in Canada) had on average less than one child (0.88). In the 1996 Census, the same arrival cohort of immigrants, having already spent six to ten years in Canada, had slightly over one child (1.06), and around 1.08 in 2001, after having lived in Canada between 11 and 15 years. Table 2 easily shows that the mean number of children of previous arrival cohorts of immigrants was higher than the 1991 arrival cohort at any point in time, while that of those who entered Canada after 1991 was lower. Regarding age at immigration, women immigrating at a young age have a similar or even lower number of children than Canadian-born females, while those immigrating later in life have more. Finally, as expected, fertility behavior is highly correlated with cultural norms regarding fertility in the source country (Blau et al. 2008; Fernandez and Fogli 2006, 2009; Ford 1990; Khan 1994). ${ }^{11}$ Immigrants from Europe (except Eastern Europe, the UK and Ireland), Mexico, Central America, Middle East and North Africa have substantially more children than Canadian born women.

(Table 2 here)

\subsection{The Fertility of Immigrants}

The estimates we report in the tables and graphs of the following subsections correspond to relative fertility rates of immigrant females as compared to those of Canadian born females. Models include controls for age, marital status (single, married/CL, or divorced/separated), province of residence, non census metropolitan areas of residence, and highest educational attainment. In order to control for the decrease in fertility over the period, we include dummy indicators for each census year. These control variables consistently show the same effect on

\footnotetext{
${ }^{11}$ Nonetheless, some migrants arriving in Canada will likely have better access to contraceptive methods during the remaining years of their fertile life than in their country of birth. That should affect their ultimate fertility, independently of their cultural heritage.
} 
fertility across all specifications. Fertility increases with age until women reach their late thirties, and then it plateaus. Fertility rates are higher for married/CL and previously married/CL women and for the least educated. Although we do not report all control variables in the tables, they are available upon request.

There is some controversy in the literature about whether or not it is appropriate to include controls for income in fertility analysis. Income measures reflect the respondents' decisions to enter the labor force. Fertility and labor market decisions (which ultimately affect income) are so intertwined that it is not realistic to regard them as exogenous to one another. Females with strong preferences for work may also have low preferences for child rearing, and this may introduce selection bias in our estimates. The direction of the bias is not straightforward. To the extent that children are a normal good, females with more income may have more children, since they can afford to pay for the extra services involved in raising children. However, women may have higher incomes precisely because they reduced or postponed their fertility. Overall, considerations of joint labor market and fertility decisions require special modelling that is beyond the scope of this paper. For this reason we have decided not to include income controls in our analysis. Note, however, that the inclusion of education and marital status in the analysis captures some important dimensions of economic well-being and to some extent help us to control for income. ${ }^{12}$

Our initial estimate of immigrant fertility rates is reported in the first regression of panel A of Table $3 .^{13}$ The basic model includes, besides the controls specified above, only an indicator for immigrant status. We report in the first column the relative fertility rate of an immigrant over a Canadian born woman, keeping constant other factors. Immigrant females have significantly higher fertility rates than the Canadian born - around 1.10 times higher, or immigrants have, on average, $10 \%$ percent more children than the Canadian born, after taking into account other factors. ${ }^{14}$

(Table 3 here)

\footnotetext{
${ }^{12}$ We have computed all regressions without controlling for education or marital status and patterns remain unchanged.

${ }^{13}$ We perform a goodness of fit Chi2 test to assess the null hypothesis that the data are indeed Poisson distributed and fail to reject the null.

${ }^{14}$ When we calculate the average predicted number of children for a married female between 35 and 40 years of age and keep the education level at the mean for each group, native born have an average of 1.77 children and immigrants 1.85 .
} 


\section{Understanding fertility assimilation: Age at Immigration}

Studies on immigrant outcomes generally place significant emphasis on assimilation. Immigrants may initially differ from the native-born population because they have different preferences, expectations or endowments. As immigrants spend time in the host country, those preferences and endowments may change and subsequently affect their fertility choices and (plausibly) make them more similar to those of native born. Typically as a way to account for potential assimilation, researchers interested in immigrant outcomes include age at immigration as one of the covariates of their model. This variable measures how the outcome of interest varies depending on how long the immigrant has been exposed to the local environment. There are different mechanisms through which age at arrival may be relevant to immigrant outcomes. Early arrival affords the person more time in the host country and increases the likelihood that the young migrant attends school and understands early in life the rules and institutions governing the socio-economic life of the receiving country.

In addition, age at immigration may also matter if there are critical ages at which individuals learn a particular behavior or skill, such as the local language. Bleakley and Chin (2010) point to research that finds physiological changes in the children's brain at the onset of teenage years that hamper their ability to learn additional languages. In their paper, they identify a critical age, around 8 or 9 years of age, for achieving English fluency among migrants in the US. After that "critical period", they show that the outcomes of immigrants from non-English speaking countries systematically differ from those of other migrants. In the case of fertility, there could be an additional effect if there is a particular age at which cultural norms regarding fertility are already formed (for instance, the onset of puberty). This could be reinforced by the existence of taboos associated with sexual behaviour, contraceptive methods, or the role of women in the labor market, among others, that set hurdles for young migrants to learn alternative views regarding fertility behaviour.

In view of this discussion, we introduce age at immigration in our models to see whether such a discontinuity appears in the fertility behaviour of child immigrants. In our discussion we focus on immigrants arriving as children (18 years of age or younger) before the common ages of family formation. Individuals migrating before age 18 are likely to come with their parents and hence, their "decision” to immigrate is plausibly independent of other variables affecting fertility such as labour market participation, education or their own family formation. Those immigrating 
as adults, however, are more likely making these decisions jointly. Nevertheless, the sample we use includes all migrants regardless of age at arrival. To compare the patterns of child immigrants to those of young adults, the model includes yearly dummies for age at immigration up until age 25 and, then, an additional indicator for all those who migrated after age 25.

(Table 4 here)

Table 4 shows the results of a Poisson regression of the form

$$
F_{i}=\exp \left\{\sum_{j=0.5}^{25}\left(\beta_{j} A_{j i}\right)+\gamma \operatorname{Oldimm}_{i}+\sum_{k}^{N}\left(\theta_{k} P O B_{k i}\right)+\alpha X_{i}+\varepsilon_{i}\right\}
$$

where we use a full set of indicator variables for each age at immigration $A_{i}$ from under age 1 to age 25, an indicator for immigrants arriving after the age of 25 (oldimm), a set of indicators $P O B_{j}$ for the countries (or groups of countries) of origin, and a vector of demographic variables $X$ (i.e. age, marital status, province, education, rural indicator, census year).

In the first column of Table 4 we omit the indicators for place of birth. In this case, the fertility outcomes of individuals arriving before age 2 are similar to those of natives. ${ }^{15}$ However, in the second column, once place of birth indicators are included, the estimated relative fertilities for all ages of arrival are significantly different from 1 (the baseline for native born). The two sets of estimated fertility rates are shown in Figure 2. Table 1A in the appendix shows the estimates of places of birth indicators included in the second column in Table $4 .^{16}$

(Figure 2 here)

What is interesting from figure 2 is that it shows no evidence of an obvious discontinuity by age at immigration in the fertility of immigrants. Rather, fertility increases gradually with age at immigration until the middle teens, then at a faster pace during the late teens and early twenties, after which it diminishes. Further, the result is not driven by intermarriage, as could be the case if those immigrating at a younger age are also more likely to intermarry and adjust their fertility to that of the native born (Meng and Gregory, 2005). Immigrants in mixed marriages (married to

\footnotetext{
${ }^{15}$ In a separate model that only includes age and province of residence, the fertility behaviour of individuals migrating up to age 6 is indistinguishable from that of natives.

${ }^{16}$ The reference category for place of birth indicators corresponds to those born in the USA. Changing the reference category will shift the predicted fertility rate by age at immigration accordingly but the shape of the profile will remain the same.
} 
native born Canadians) also show this pattern. ${ }^{17}$ Immigrants arriving after 25 years of age have, on average, $7 \%$ higher fertility rates than the native born.

Fertility preferences are greatly influenced by social attitudes toward fertility, contraceptive measures, gender preferences, and out of wedlock childbearing, among many others that are part of an individual's cultural background. We try to account in part for these differences in cultural background by controlling for the woman's area of origin. Further, given the changes in the composition of immigration to Canada documented in the introduction, this is an important part of the analysis. ${ }^{18}$ In this regard, the estimates in the second column of table 4 are net of the influence of cultural preferences for fertility, as estimated through area of origin and isolate the effect of the changing composition of the source country of immigration over the census years.

Area of origin has already been shown to be relevant in explaining variation of fertility outcomes in different contexts. Anderson (2004), for example, finds important differences in levels of childbearing propensities between women from different countries of origin among migrants to Sweden from the 1960s to the 1990s. More recently, Georgiadis and Manning (2011) analyze Muslim assimilation (Pakistanis and Bangladeshis) into British society as compared to other migrant groups in different dimensions that include fertility. Guinnane et al. (2006) find that, at the turn of the XX century, Irish immigrants to the US had lower fertility than women in Ireland but higher fertility than US native born. Similar research for the United States for more recent periods has been undertaken by Kahn (1994) and Parrado and Morgan (2008), among others. The majority of these studies report substantial differences in fertility by ethnicity, although these tend to shrink for the second generation. It is important to note that policies in the country of arrival that affect the expectations of the extent and the pace at which newcomers

\footnotetext{
${ }^{17}$ The observed peak in fertility for those arriving in the late teens could be attributed in part to "child brides", very young women that are brought to western countries to enter into arranged marriages with males of their same culture. This phenomenon has received attention in the context of European migration, which receives large numbers of immigrants from countries favoring these arrangements. We do not have information on age at first marriage in the Census, but we have looked at the fraction of mixed marriages (to native born Canadian) by age at immigration and area of origin and find no increase in this fraction for ages 14 to 17 among the Middle East, North Africa or South Asian immigrants. In fact young immigrants from the Middle East are less likely to marry immigrants than those arriving at later ages. This supports the general perception that this phenomenon is much less relevant in Canada, a country that receives fewer immigrants from cultures favoring arranged marriages and where immigrants are highly educated. Further as shown later in the paper the peak is observed across all source countries.

${ }^{18}$ Until the 1981 Census, the majority of immigrant women with children under five were originally from Europe. However, Asian immigrant mothers overtook all other continents in the 1996 Census for this category. In our sample, and throughout the census years, around one-fifth of the immigrants were born in the American continent (Table 1), 6\% in the Middle East, and 1\% in Pacific countries.
} 
have to become part of the local culture may play a role in the speed at which those behaviors adapt. For example, multiculturalist movements that encourage cultural continuity of newcomers could potentially deter the assimilation to the receiving culture. In other instances, policies in the country of origin either pro-natalistic (e.g., Ceceascu's regime) or restrictive (e.g., China's one child policy) may have shaped fertility of migrants before their arrival in such a decisive way that their behavior in the country of destination reflects a readjustment (if at all) of their preferences after breaking free of policy constraints. Finally, whether the neighbourhoods where immigrants live are more or less segregated may reinforce or weaken the relevance of ethnic human capital (i.e. the average education of the group) and culture in the individual's outcomes (as shown for education or earnings in Borjas 1992, 1995).

As noted, Table 1A portrays the estimates of the dummies for different places of birth included in the second model of Table 4 (and Figure 2). Immigrants from the Caribbean and Central America have high fertility rates. Fertility rates of immigrants from Mexico stand around 1.4 times higher than those of Canadian born. Other immigrant groups with high fertility rates are those originating in Africa (except South Africa), the Middle East, and Southern Asia. Eastern European immigrants, as well as those from elsewhere in Asia, have relatively low fertility rates in comparison. Chinese immigrants exhibit the lowest fertility rate of all groups, only 0.76 times that of the Canadian born. ${ }^{19}$

The question that rises then is whether the fertility of all immigrant groups follows the age at immigration pattern described for the general population or whether there are substantial differences between groups. To answer this question we have interacted place of birth with age at immigration groups. To avoid running into problems of small cells, we have categorized age at immigration into five groups: those immigrating as pre-school children (aged five or less at the time of immigration), those immigrating as elementary school children (aged 6 to 11 at the time of immigration), those immigrating in their early teens (ages 12 to 15) and likely to enter school in junior high school, those immigrating in the late teens (between ages 16 to 19) and still highly likely to receive Canadian schooling, and finally those immigrating at 20 years of age or older. Our categorization according to ages at which a child is more likely to attend a certain type of school is intended to avoid mixing in the same group children entering different school levels.

\footnotetext{
${ }^{19}$ The predicted fertility of a representative mother in the most prolific groups is well above both the replacement level of 2.1, and that of the whole population of immigrants (1.85)
} 
While elementary schools tend to be small and local, high school institutions are often larger and can be further away from the child's neighbourhood, particularly in large cities. In addition, social interaction among children changes with age and the type of school institution they attend (Khmelkov and Hallinan, 1999).

\section{(Figure 3 here)}

Figure 3 shows the cumulative effect of the interaction between the age groups and broad areas of origin (US-Europe, Middle East, South Asia, Other Asia plus the Pacific, Africa, and South America - including Central America) from the model in Table 5. All places show the same increasing pattern of fertility by age at immigration that peaks in the late teens. The difference across country groups is one of levels fertility. Immigrants from the Middle East and South America show high fertility rates even if arriving at a young age (approximately 20\% higher approximately than the native born), while immigrants from Africa and South Asia have relatively low fertility rates if arriving young (10\% lower than the native born) and immigrants from the rest of Asia have very low fertility rates if arriving young (20\% lower than the native born). These patterns seem to suggest that, unlike other types of immigrant assimilation, fertility assimilation is a relatively smooth process. However, cultural differences determine the extent of such assimilation. For most groups age at immigration implies assimilation in the usual sense, the younger they arrive to the country, the more similar their fertility is with respect to the native born. Asian immigrants from areas other than South Asia, exhibit relatively low fertility at all ages at immigration compared to other immigrants. As a result the fertility behavior of the older immigrants in this group is closer to that of the native born than that migrating as young children. Exploration of the cultural differences in the intergenerational transmission of fertility is beyond the scope of this paper. However, a plausible explanation is that this group puts strong emphasis in educational outcomes of their children. To the extent that education and fertility are highly correlated, very young Asian immigrants will show lower fertility through the effect of education. ${ }^{20}$ Both the estimated IRR and the cumulative effect of the area of origin group, age at immigration groups and their interaction are shown in Table 5 for more general groups of countries. Table 6 presents the estimated IRR from a Poisson regression that includes more detailed areas of origin.

\footnotetext{
${ }^{20}$ Note that thee model controls for educational achievement, unfortunately it is not flexible enough to allow for differential effects of education by source area and age at immigration.
} 
(Tables 5 \& 6 here)

\subsection{How does age at immigration work? Language barriers}

When examining educational attainment or labor outcomes of young immigrants, fluency in destination country language plays a key role (see e.g. Kossoudji, 1988; Chiswick and Miller, 2001, 2004; Dustmann, 1994; Dustman and van Soest, 2002; Bleakley and Chin, 2004). Among others, studies by Leslie and Lindley (2001) and Dustmann and Fabbri (2003) find that lack of fluency in English has a detrimental impact on the employment and earnings of ethnic minority men and women in Britain. In the case of fertility, mother tongue may also impact the ability of the child-migrant to form preferences about fertility using local cultural cues acquired through school and peer networks. Previous analyses have found greater English fluency to be associated with lower fertility in the US (Sorenson 1988; Swicegood et al. 1988; Bleakley and Chin 2010).

The Canadian census does not have a measure of fluency of the official language, but only asks whether the individual speaks one of the official languages. Further, because the ability to speak an official language is one of the criteria in the selection of immigrants, the variable is mostly uninformative. ${ }^{21}$ There is, however, additional information that can be used to obtain a measure for fluency. The Canadian immigration literature has typically measured fluency by looking at mother tongue, the language that individuals first understood and they can still understand. The advantage of mother tongue relative to self-reported fluency is that it is a relatively exogenous variable. Further, mother tongue and its distance to the official tongue, has proven to be important on labor market and education assimilation. For example, immigrant men in Europe coming from a country where the language spoken belongs to the same language family group as the destination country experience a $9 \%$ earnings premium over other immigrants (Adsera and Chiswick, 2007).

We introduce an indicator for whether the individual had an official mother tongue (OMT) in a province that primarily uses that official mother tongue. ${ }^{22}$ If language barriers difficult the

\footnotetext{
${ }^{21}$ Immigrants to Canada are admitted through three main categories (skilled, family and refugees). Skilled immigrants (currently around 60\% of all new admissions) are assessed on the basis of their age, education, language ability and labor market characteristics.

${ }^{22}$ This is to account for the fact that although Canada recognizes two official languages (English and French), French is used mostly in Quebec, whereas English is generally used elsewhere. This definition of OMT has the problem that we know only where individuals reside at the time of the census. Using a standard definition of official mother tongue as "individual first spoke either French or English as a child” yields similar results
} 
assimilation of local norms governing fertility, we would expect that immigrants whose first language was not one of the Canadian official languages to have different fertility behavior than those whose mother tongue was English or French.

Model II in table 3 shows the influence of mother tongue on the fertility behaviour of immigrants. Among the native born, those who had an OMT have slightly higher fertility rates (3\% higher) than native born Canadians who do not. This later group is mainly composed by the native born children of immigrants. The result agrees with previous findings in the literature reporting that the second generation of immigrants have on average lower fertility levels than their immigrant parents (Ferrer and Adsera, 2010). Immigrants who do not have an OMT have higher fertility than Canadian born individuals who do not have an OMT (14\% higher). To better understand the interaction between immigrant and mother tongue indicators, we report in the first column of Panel B how the relative fertility rates of immigrants with an OMT compares to that of the other groups. The z-statistic of whether the difference between the groups is statistically significant is shown in column 2. Immigrants with an OMT have significantly higher fertility than the native born. More importantly, they have only slightly lower fertility than other immigrants (2\% lower), suggesting that that having an OMT does not have a big impact on the fertility of immigrants. ${ }^{23}$

It is well recognized that fluency in the language of the destination country is strongly influenced by age at immigration among other things (Chiswick 1991; Espenshade and Fu 1997 Espinosa and Massey 1997; Stevens, 1992 and 1999). Akresh (2007) finds that the younger immigrants arrive to the US and the longer immigrants they have lived in the country, the higher their frequency of English use with friends, at work, at home, and with a spouse. Hence, it could be the case, however, that the impact of OMT on fertility depends on age at immigration. This will happen if there is an immigration age after which language acquisition becomes problematic and this influences the assimilation of cultural norms regarding fertility (see Bleakley and Chin 2010, for example). If language is the channel through which age at immigration affects fertility, we expect to see immigrants who have an OMT behave differently than the rest and be more similar to Canadian born. Further, we expect that very young immigrants, those arriving before the age of 5 (or even in early elementary school), will behave similarly regardless of the mother

\footnotetext{
${ }^{23} 12.5 \%=\exp (\ln (1.034)+\ln (1.143)+\ln (0.951))$
} 
tongue, as they are unlikely to experience language difficulties in the assimilation of fertility behaviour.

To study this possibility we estimate a model that includes a set of interactions of the age at migration with an indicator for whether the language first spoken by the native as a child was an official mother tongue (OMT). The Poisson regression we run is of the form

$$
\begin{aligned}
& F_{i}=\exp \left\{O M T_{i}+\sum_{j=0.5}^{25}\left(\beta_{j} A_{j i}+\phi_{j} A_{j i} * O M T_{i}\right)+\gamma_{1} \text { Oldimm }_{i}+\gamma_{2} O M T_{i} * \text { Oldimm }_{i}\right. \\
& \left.+\sum_{k}^{N}\left(\theta_{k} P O B_{k i}\right)+\alpha X_{i}+\varepsilon_{i}\right\}
\end{aligned}
$$

where we include a full set of interactions between age at immigration indicators and the OMT indicator.

\section{(Table 7 here)}

Table 7 presents estimates from an interaction between the OMT indicator and the indicators for each age at immigration from equation (4). The estimates are represented in Figure 4 and show that both types of immigrants follow a similar pattern. The fertility of immigrants who have an OMT also increases with age at immigration relative to that of the native born. The last column of Table 7 shows that an F-test of the differences in fertility between immigrants and native born with OMT is significant for all ages of migration. Further, immigrants who do not have an OMT show higher fertility rates than the native born, even if they arrive at very young ages. $^{24}$

The result suggests that language fluency proxied by the first language the immigrant spoke as a child, is not a barrier in the assimilation of fertility as has been found for the US data (Bleakly and Chin, 2010). Fertility does increase with age at immigration, regardless of mother tongue. More generally, this finding is in contrast with the literature that identifies language as a barrier in educational attainment and labour market performance of immigrants (Schaafsma and Sweetman, 2001; Bleakley and Chin 2004). If language was the key barrier in fertility assimilation, individuals with an OMT should exhibit fertility levels similar to natives instead of an increasing pattern of fertility with age at migration.

\footnotetext{
${ }^{24}$ This result is robust to considering English and French mother tongues separately.
} 
(Figure 4 here)

\subsection{Age at Immigration and Education}

Age at immigration is likely to influence other variables affecting fertility. For instance, late age of arrival may limit integration into the school system, increasing the cost of acquiring higher education. In turn, a lower educational attainment is usually associated with higher fertility. To assess this possibility we look into the fertility of immigrants arriving at different ages conditioning on whether or not they attained a university degree. We expect that if age at immigration affects fertility through education, immigrants with a given educational attainment will behave like similarly educated native born Canadians. Table 8 shows the results of interacting the age at immigration indicators with the university education indicator, based on the following equation:

$$
\begin{aligned}
& F_{i}=\exp \left\{\text { Univ }_{i}+\sum_{j=0.5}^{25}\left(\beta_{j} A_{j i}+\phi_{j} A_{j i} * \operatorname{Univ}_{i}\right)+\gamma_{1} \text { Oldimm }_{i}+\gamma_{2} \text { univi }_{i} * \text { Oldimm }_{i}\right. \\
& \left.+\sum_{k}^{N}\left(\theta_{k} \operatorname{POB}_{k i}\right)+\alpha X_{i}+\varepsilon_{i}\right\}
\end{aligned}
$$

The estimates, for university and non university educated immigrants, are represented in Figure 5, which shows the fertility rate by age at immigration of immigrants with and without university education, relative to similarly educated native born Canadians. ${ }^{25}$ Immigrants without university education follow the same increasing pattern found in Table 4 (and Figure 2), even if immigrating at very young ages. Educated immigrants, however, have a much flatter profile, particularly if migrating before age 18 when integration in the Canadian school system takes place. The last column in Table 8 shows the cumulative effect of university education and age at immigration on immigrant fertility together with the p-value of an F-test on the significance of the differences in fertility between immigrants and native born with university education. Results indicate that the differences between both groups are in general not significant for those migrating until age 17.

(Table 8 \& Figure 5 here)

\footnotetext{
${ }^{25}$ Results are robust to different specifications of post secondary education that include college or other forms of post secondary. Further, when we interact age at immigration with three levels of schooling - less than high school, high school and college - the difference in fertility with respect to natives appears only among those who did not finish compulsory education.
} 
Results in this section suggest that education is an important determinant of fertility among child immigrants. Indeed, for child immigrants educational achievement is highly associated with their degree of fertility assimilation. ${ }^{26}$ This, however, corresponds to a reduced form estimate, and though suggestive, it fails to account for the potential endogeneity of education decisions. Proper analysis of this channel needs to take into account the joint decision of schooling and fertility and how preferences regarding these variables are transmitted intergenerationally. Hence, unobserved heterogeneity may determine both education and fertility decisions, creating a selection problem: women who have low preferences for child bearing choose high levels of education. This would give the appearance that education causes low fertility, even though the underlying cause is unobserved heterogeneity in preferences for fertility. This is a serious problem that plagues most research concerning the fertility decisions of women, as most variables that determine fertility are likely to be choice variables themselves. Unfortunately, the conventional methods to deal with this type of selection bias require information that it is not available to us, such as longitudinal or panel data, or instrumental variables. Nevertheless we believe that these reduced form estimates indicate that the key to understanding immigrant fertility assimilation lies in the interplay between education and fertility

\section{Conclusions}

Our study shows that immigrant fertility is generally higher than that of Canadian born women, though not by much. We focus on the fertility behaviour of individuals immigrating as children and uncover a non linear relationship between fertility and age at immigration. Contrary to what happens with other immigrant outcomes where a sharp discontinuity in outcomes relative to natives is found around arrival at middle school ages for those with a different mother tongue than that of the receiving country, fertility increases continuously with age at immigration until those arriving in their late teens and diminishes somewhat afterwards. This assimilation profile is present among immigrants coming from different cultural backgrounds, although their actual fertility levels vary with their country of origin. We rule out language acquisition as the mechanism through which fertility assimilation may happen. Fertility behaviour of immigrants

\footnotetext{
${ }^{26}$ The result appears robust for all source areas of immigration. In separate estimates, available upon request, we find that immigrants from non western economies show large fertility differences between those who are educated (post secondary education) and those who are not within the same country of origin. The largest differences correspond to Mexican and Central American immigrants, followed by those from the Middle East, Central and Eastern Africa.
} 
with an official mother tongue also differs from that of natives. Educational attainment, on the other hand, appears to be strongly related to this pattern of fertility assimilation, which seems to occur only among less educated immigrants. University educated young immigrants behave like natives. Although not included in the paper we have also found similar results after controlling for language spoken at home, intermarriage, and language of spouse, among other things.

In 2006, international migration was responsible for about two-thirds of total population growth in Canada and was the main contributor to Canadian labour force growth (70\%). In the context of rising demographic dependency ratios due to low population growth and the aging of the baby boom generation, immigration is a key factor to sustaining current levels of public services in Canada. However, this strategy not only relies on the direct relief that new entering population provides to dependency ratios, but also on the ability of immigrants to economically assimilate into Canadian society. In this context, the interplay of fertility and immigration rates has also an important role in determining the future economic growth of Canada. Although high fertility rates among first generation immigrants may help boost overall fertility rates and sustain population growth, they could also hinder the economic assimilation of female immigrants and impact the economic wellbeing of immigrant families and the human capital investments of their children. On the other hand, highly educated immigrants may exhibit low fertility behaviour but will, presumably integrate better in the economy. Our analysis highlights the importance of this trade-off in devising immigration policies.

Many questions are left unanswered to unveil the mechanism through which fertility assimilation occurs. In particular, future research should focus on the endogeneity of educational choices and how they are tied up with labour market and fertility outcomes. 


\section{References}

Adsera, A. 2004. "Changing Fertility Rates in Developed Markets: The Impact of Labor Market Institutions.” Journal of Population Economics 17: 17-43.

Adsera, A. and B. R. Chiswick, 2007. “Are There Gender and Country of Origin Differences in Immigrant Labor Market Outcomes Across European Destinations?”, Journal of Population Economics, Vol. 20 (3), 495-526

Anderson, G. 2004 “Childbearing after Migration: Fertility Patterns of Foreign-Born Women in Sweden.” International Migration Review 38 (2): 747-74

Akresh, I. R. 2007 “'Contexts of Language Use Among Immigrants in the United States.” International Migration Review 41:930-955.

Aydemir, A. and Skuterud, M. (2005) "Explaining the Deteriorating Entry Earnings of Canadian Immigrant Cohorts: 1966-2000”, Canadian Journal of Economics, Vol. 38(2), pp. 641-72.

Becker, G. 1981. A Treatise on the Family. Cambridge, MA: Harvard University Press,.

Bélanger, A., and S. Gilbert. 2003. "The Fertility of Immigrant Women and Their CanadianBorn Daughters.” Report on the Demographic Situation in Canada 2002, 91-209.

Bélanger, A., L. Martel, and É. Caron-Malenfant. 2005. "Population Projections for Canada, Provinces and Territories 2005-2031.” Statistics Canada catalogue No. 91-520-XIE.

Blau, F.D. 1992. "The Fertility of Immigrant Women: Evidence from High Fertility Source Countries.” In Immigration and the Work Force: Economic Consequences for the United States and Source Areas, edited by G.J. Borjas and R.B. Freeman, 93-133. Chicago: UCP.

Blau, F.D., L . Kahn, A. Yung-Hsu Liu, and K.L. Papps. 2008. “The Transmission of Women’s Fertility, Human Capital and Work Orientation across Immigrant Generations.” NBER working paper no. 14388.

Bleakley, H. \& A. Chin, 2004. "Language Skills and Earnings: Evidence from Childhood Immigrants," The Review of Economics and Statistics, vol. 86(2), pages 481-496.

Bleakley, H. \& A Chin, 2010. "Age at Arrival, English Proficiency, and Social Assimilation among US Immigrants," American Economic Journal: Applied Economics, vol. 2(1), pages 165-92.

Borjas, G. 1992, “Ethnic Capital and Intergenerational Mobility,” Quarterly Journal of Economics 107(1), 123-150.

Borjas, G. 1995, “Ethnicity, Neighborhoods, and Human-Capital Externalities,” American Economic Review 85(3), 365-390.

Chiswick, B.R. 1991, "Speaking, Reading, and Earnings among Low-Skilled Immigrants”, Journal of Labor Economics, Vol. 9, No. 2 pp. 149-170

Chiswick, B. R. and P. W. Miller 2001 "A Model of Destination-Language Acquisition: Application to Male Immigrants in Canada.’ Demography 38:391-409.

Chiswick, B. R. and P. W. Miller 2004 “'Linguistic Distance: A Quantitative Measure of the Distance between English and Other Languages.” IZA Discussion Paper No. 1246. 
Coleman, D. 2006. "Immigration and Ethnic Change in Low-Fertility Countries, Demographic Transition.” Population and Development Review 32 (3): 401-46.

Dustmann, Christian. 1994. "Speaking Fluency, Writing Fluency and Earnings of Migrants.” Journal of Population Economics 7, pp. 133-56.

Dustmann, Ch. and A. van Soest (2002): “Language and the Earnings of Immigrants.” Journal Industrial and Labor Relations Review” 55 (3), pp.473-492.

Dustmann, Ch. And F. Fabbri 2003.Language proficiency and labour market performance of immigrants in the UK, Economic Journal 113 (489): 695-717.

Espenshade, T. J. and H. Fu 1997 “'An Analysis of Language Proficiency Among Immigrants.”, American Sociological Review 62(2):288-305.

Espinosa, K. E. and D. S. Massey 1997 “'Determinants of English Proficiency Among Mexican Migrants to the United States.” International Migration Review 31(1):28-50.

Fernandez, R., and A. Fogli. 2006. "Fertility: The Role of Culture and Family Experience.” Journal of the European Economic Association.

Fernandez, R. \& A. Fogli, 2009. "Culture: An Empirical Investigation of Beliefs, Work, and Fertility," American Economic Journal: Macroeconomics, Vol.1(1): 146-77

Ferrer, A.M. and A.Adsera. 2010. The Fertility Decisions of Canadian Immigrants, In Canadian Research on Immigration. Edited by Arthur Sweetman, Ted McDonald and Elizabeth Ruddick, John Deutchs Institute of Economic Policy, Queen's University. McGill-Queen's Press.

Ferrer, A.M., D. Green, and W. Craig Riddell. 2006. "The Effect of Literacy on Immigrant Earnings.” Journal of Human Resources 41 (2): 380-410.

Ford, K. 1990. "Duration of Residence in the United States and the Fertility of U.S.. Immigrants.” International Migration Review 24 (1): 34-68.

Galor, O., and D. Weil. 1996. “The Gender Gap, Fertility and Growth.” American Economic Review 86: 374-87.

Georgiadis, A., and A. Manning. 2011. “Change and Continuity among Minority Communities in Britain.” Journal of Population Economics 24: 541-568.

Green, A. and D. Green, (2004) “The Goals of Canada’s Immigration Policy: A Historical Perspective”, Canadian Journal of Urban Research, Volume 13, Issue 1, pages 102-139.

Guinnane, Timothy W. \& Moehling, Carolyn M. \& O Grada, Cormac, 2006. "The Fertility of the Irish in America in 1910," Explorations in Economic History 43 (3): 465-85.

Hervitz, H.M. 1985. "Selectivity, Adaptation, or Disruption? A Comparison of Alternative Hypotheses on the Effects of Migration on Fertility: The Case of Brazil.” International Migration Review 19, 293-317.

Kahn, J. 1994. "Immigrant and Native Fertility during the 1980s: Adaptation and Expectations for the Future.” International Migration Review 28 (3): 501-19.

Kalbach,W. 1970. “The Impact of Immigration on Canada's Population.” Queen's Printer, Ottawa.

Khmelkov, V. and M. Hallinan, 1999 Organizational Effects on Race Relations in Schools, Journal of Social Issues, vol.55(4), pp. 627-645 
Kossoudji, S.A. 1988. "The Impact of English Language Ability on the Labor Market Opportunities of Asian and Hispanic Immigrant Men”. Journal of Labor Economics. 6(3):205228.

Leslie, D. and J. Lindley, 2001. "The Impact of Language Ability on Employment and Earnings of Britain's Ethnic Communities”, Economica, Vol. 68, (272): 587-606

Meng, Xin and Robert G. Gregory, 2005, “Intermarriage and economic assimilation of immigrants”, Journal of Labor Economics, 23(1), pp.135-176.

Ng, E., and F. Nault. 1997. "Fertility among Recent Immigrant Women to Canada, 1991: An Examination of the Disruption Hypothesis.” International Migration 35 (4): 559-80.

Parrado, E.A., and S.P. Morgan. 2008. “Intergenerational Fertility among Hispanic Women: New Evidence of Immigrant Assimilation.” Demography 45.

Picott and Sweetman, 2005 “The Deteriorating Economic Welfare of Immigrants and Possible Causes”, Analytical Studies Branch Research Paper Series. Catalogue no. 262. Ottawa: Statistics Canada.

Picot, G. F. Hou and S. Coulombe (2007) “Chronic Low Income and Low-income Dynamics Among Recent Immigrants”, Analytical Studies Branch Research Paper Series, No. 294. Satatistics Canada.

Ram, B., and M.V. George. 1990. “Immigrant Fertility Patterns in Canada, 1961-1986.” International Migration 28 (4): 413-26.

Schaafsma, J., and A. Sweetman 2001. “Immigrant Earnings: Age at Immigration Matters.” Canadian Journal of Economics 34 (4): 1066-99.

Sobotka, T. (2008). “The rising importance of migrants for childbearing in Europe. Demographic Research 19(9): 225-248.

Sorenson, A.M. 1988. The Fertility and Language Characteristics of Mexican-American and Non-Hispanic Husbands and Wives, The Sociological Quarterly, Vol. 29, (1) :111-130

Stevens, G. 1992. “'The Social and Demographic Context of Language Use in the United States.” American Sociological Review 57:171-785.

Stevens, G. 1999. “'Age at Immigration and Second Language Proficiency Among Foreign-Born Adults.”' Language and Society 28:555-578.

Swicegood, G., F. D. Bean, E. Hervey Stephen, and W. Opitz. 1988. "Language Usage and Fertility in the Mexican Origin Population of the United States." Demography 25(1):17 34.

United Nations 2000. Replacement Migration: Is It a Solution to Declining and Ageing Population? New York: United Nations Population Division.

Vezina, M. and M. Turcotte 2009. "Forty-Year Old Mothers of Pre-School Children: A Profile” Canadian Social Trends. Statistics Canada. 
TABLE 1. Summary Sample Statistics for Canadian Born and Immigrants

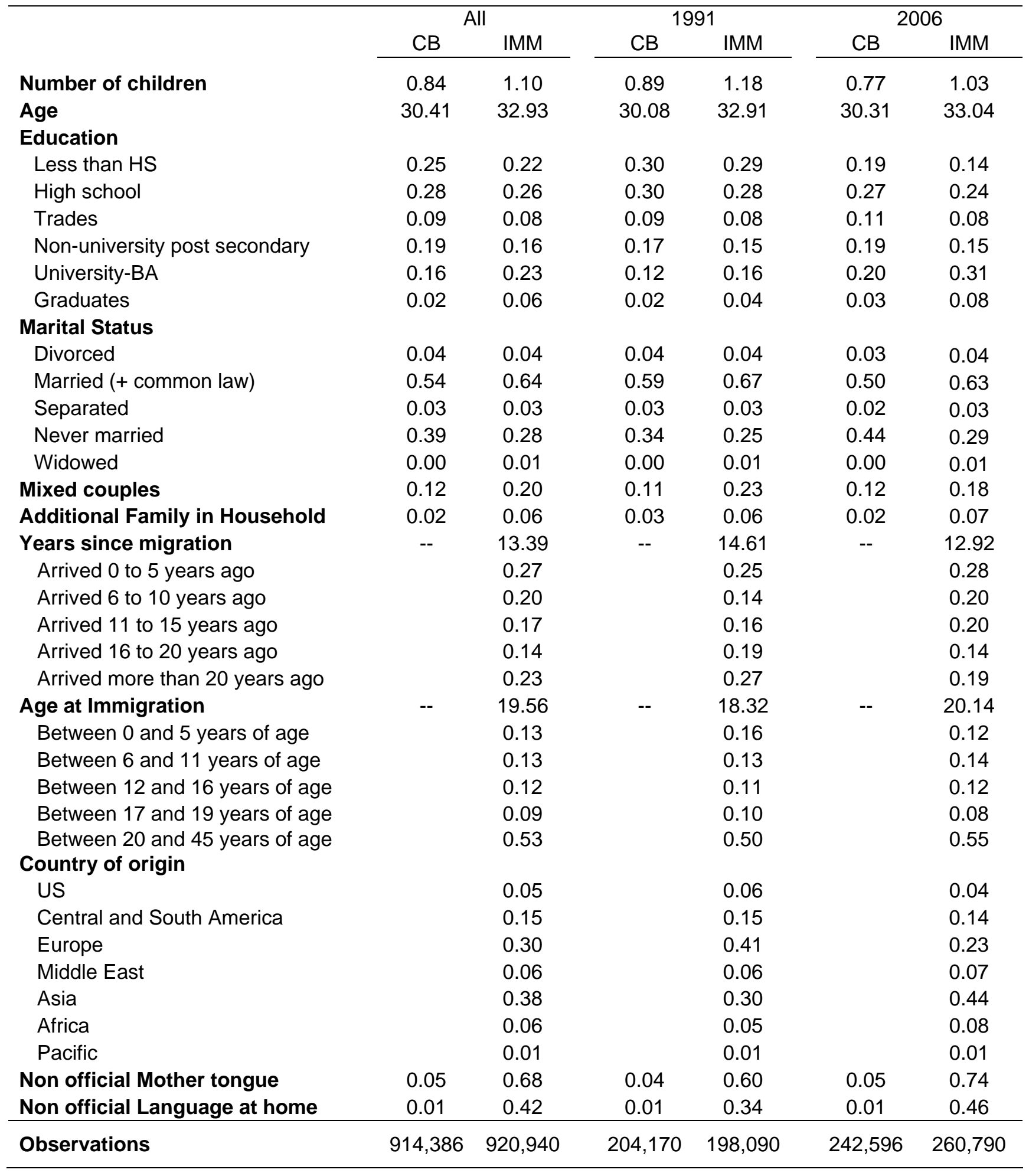


TABLE 2. Sample Mean Number of Children for Women Aged 16-45 by Census Year

\begin{tabular}{|c|c|c|c|c|}
\hline & 1991 & 1996 & 2001 & 2006 \\
\hline Non-Immigrant & 0.89 & 0.88 & 0.84 & 0.77 \\
\hline Immigrant & 1.18 & 1.11 & 1.08 & 1.03 \\
\hline \multicolumn{5}{|l|}{ Years since migration } \\
\hline 0 to 5 & 0.88 & 0.84 & 0.88 & 0.85 \\
\hline 6 to 10 & 1.11 & 1.06 & 1.00 & 1.00 \\
\hline 11 to 15 & 1.22 & 1.18 & 1.08 & 1.02 \\
\hline 16 to 20 & 1.26 & 1.25 & 1.23 & 1.08 \\
\hline More than 20 & 1.41 & 1.36 & 1.35 & 1.31 \\
\hline \multicolumn{5}{|l|}{ Age at immigration } \\
\hline 0 to 5 years old & 0.77 & 0.77 & 0.72 & 0.68 \\
\hline 6 to 11 years old & 0.84 & 0.77 & 0.69 & 0.57 \\
\hline 12 to 16 years old & 0.91 & 0.78 & 0.71 & 0.62 \\
\hline 17 to 19 years old & 1.32 & 1.16 & 1.07 & 1.00 \\
\hline More than 19 years old & 1.43 & 1.34 & 1.35 & 1.32 \\
\hline \multicolumn{5}{|l|}{ Country of origin } \\
\hline US & 1.11 & 1.17 & 1.18 & 1.10 \\
\hline Caribbean & 1.03 & 1.02 & 1.06 & 1.01 \\
\hline Mexico & 1.65 & 1.73 & 1.55 & 1.41 \\
\hline Central America & 1.38 & 1.33 & 1.24 & 1.17 \\
\hline South America & 1.09 & 1.07 & 1.10 & 1.06 \\
\hline UK-Ireland & 1.09 & 1.09 & 1.14 & 1.14 \\
\hline Northern and Central Europe & 1.20 & 1.12 & 1.08 & 1.03 \\
\hline Eastern Europe & 1.09 & 1.09 & 0.92 & 0.86 \\
\hline Southern Europe & 1.57 & 1.48 & 1.35 & 1.19 \\
\hline Middle East & 1.33 & 1.29 & 1.20 & 1.11 \\
\hline China & 1.01 & 0.85 & 0.78 & 0.74 \\
\hline North-East Asia & 1.07 & 0.91 & 0.84 & 0.76 \\
\hline South Eastern Asia & 1.03 & 0.89 & 0.94 & 0.95 \\
\hline Southern Asia & 1.13 & 1.25 & 1.26 & 1.23 \\
\hline North Africa & 1.35 & 1.38 & 1.31 & 1.23 \\
\hline Central Africa & 1.14 & 1.13 & 1.19 & 1.21 \\
\hline West Africa & 1.01 & 1.24 & 1.14 & 1.13 \\
\hline Southern Africa & 0.95 & 0.97 & 0.99 & 0.92 \\
\hline Eastern Africa & 0.98 & 1.00 & 1.19 & 1.18 \\
\hline Pacific & 1.03 & 1.09 & 1.09 & 1.02 \\
\hline Observations & 402,260 & 444,460 & 485,210 & 503,386 \\
\hline
\end{tabular}

Note: Differences in age structure of individuals across countries of origin in the sample are, in part, responsible for the differences in the mean number of children displayed in the table. 
TABLE 3

\section{A. Relative Immigrant Fertility by Language Background}

Relative Fertility Rate

\section{Basic Model}

Native born

Immigrant

$1.104^{\star \star \star}$

\section{Mother tongue}

Native born (re: non official mother tongue)

OMT (Official Mother Tongue)

$1.034^{\star \star *}$

Immigrant

$1.143^{\star * *}$

Immigrant x OMT

$0.951^{\star \star *}$

\section{Observations}

$1,833,526$

B. Comparison of Relative Fertility

\begin{tabular}{lcc}
\hline & (Cumulative) RFR & z \\
\cline { 2 - 3 } Immigrant OMT $=$ NB non OMT & 1.125 & 29.39 \\
Immigrant OMT $=$ NB OMT & 1.087 & 37.98 \\
Immigrant OMT $=$ Immigrant non OMT & 0.984 & -7.39 \\
\hline
\end{tabular}

Panel A, shows the results of two Poisson regressions for the number of children living at home for a sample of women 16 to 45 years old. Both include controls for age, education, marital status, census year and location of residence.

In Panel B, the first column shows the relative fertility of each group relative to immigrants with an Official Mother Tongue. The second column reports the $z$ of the significance of a test on the difference between these two groups based on the results from model II in Panel A.

$\left.{ }^{(\star \star *}\right)$ indicates significant at $\left.1 \%,{ }^{* \star}\right)$ indicates significance at 5 percent. 
Table 4. Fertility Rate by Age at Immigration relative to Native Born ${ }^{(1)}$ (P-values)

\begin{tabular}{|c|c|c|c|c|}
\hline & \multicolumn{2}{|c|}{ (I) } & \multicolumn{2}{|c|}{ (II) } \\
\hline & Effect & P-value & Effect & P-value \\
\hline \multicolumn{5}{|c|}{ Age at migration: } \\
\hline Less than 1 & 1.01 & $(0.46)$ & 1.03 & $(0.00)$ \\
\hline 1 & 1.01 & $(0.36)$ & 1.03 & $(0.00)$ \\
\hline 2 & 1.02 & $(0.01)$ & 1.04 & $(0.00)$ \\
\hline 3 & 1.02 & $(0.00)$ & 1.05 & $(0.00)$ \\
\hline 4 & 1.03 & $(0.00)$ & 1.05 & $(0.00)$ \\
\hline 5 & 1.02 & $(0.00)$ & 1.04 & $(0.00)$ \\
\hline 6 & 1.04 & $(0.00)$ & 1.06 & $(0.00)$ \\
\hline 7 & 1.07 & $(0.00)$ & 1.08 & $(0.00)$ \\
\hline 8 & 1.07 & $(0.00)$ & 1.08 & $(0.00)$ \\
\hline 9 & 1.07 & $(0.00)$ & 1.08 & $(0.00)$ \\
\hline 10 & 1.07 & $(0.00)$ & 1.08 & $(0.00)$ \\
\hline 11 & 1.07 & $(0.00)$ & 1.08 & $(0.00)$ \\
\hline 12 & 1.09 & $(0.00)$ & 1.09 & $(0.00)$ \\
\hline 13 & 1.11 & $(0.00)$ & 1.11 & $(0.00)$ \\
\hline 14 & 1.12 & $(0.00)$ & 1.12 & $(0.00)$ \\
\hline 15 & 1.13 & $(0.00)$ & 1.12 & $(0.00)$ \\
\hline 16 & 1.18 & $(0.00)$ & 1.17 & $(0.00)$ \\
\hline 17 & 1.20 & $(0.00)$ & 1.19 & $(0.00)$ \\
\hline 18 & 1.22 & $(0.00)$ & 1.21 & $(0.00)$ \\
\hline 19 & 1.24 & $(0.00)$ & 1.23 & $(0.00)$ \\
\hline 20 & 1.21 & $(0.00)$ & 1.20 & $(0.00)$ \\
\hline 21 & 1.21 & $(0.00)$ & 1.20 & $(0.00)$ \\
\hline 22 & 1.19 & $(0.00)$ & 1.18 & $(0.00)$ \\
\hline 23 & 1.16 & $(0.00)$ & 1.16 & $(0.00)$ \\
\hline 24 & 1.12 & $(0.00)$ & 1.12 & $(0.00)$ \\
\hline 25 & 1.11 & $(0.00)$ & 1.11 & $(0.00)$ \\
\hline 26 and up & 1.07 & $(0.00)$ & 1.09 & $(0.00)$ \\
\hline Place of birth & -- & & YES & \\
\hline
\end{tabular}

${ }^{(1)}$ The table shows the IRR from a Poisson regression of the number of children in the household. Both models include controls for age, education, marital status, census year, place of residence and place of birth This estimates are shown in figure 2. 
Table 5. Fertility by grouped Age at Immigration and POB

\begin{tabular}{|c|c|c|c|c|}
\hline & \multicolumn{2}{|c|}{ (I) } & \multicolumn{2}{|c|}{ (II) } \\
\hline & Effect & P-value & Cum. Effect & P-value \\
\hline USA-Europe & 0.96 & $(0.00)$ & & \\
\hline USA-Europe*(0-5) & 1.14 & $(0.00)$ & 1.02 & $(0.00)$ \\
\hline USA-Europe*(6-11) & 1.04 & $(0.00)$ & 1.06 & $(0.00)$ \\
\hline USA-Europe*(12-16) & 1.04 & $(0.00)$ & 1.10 & $(0.00)$ \\
\hline USA-Europe*(17-19) & 1.10 & $(0.00)$ & 1.20 & $(0.00)$ \\
\hline USA-Europe*(20-25) & 1.08 & $(0.00)$ & 1.11 & $(0.00)$ \\
\hline Middle East & 1.36 & $(0.00)$ & & \\
\hline Middle East *(0-5) & 0.88 & $(0.00)$ & 1.12 & $(0.00)$ \\
\hline Middle East *(6-11) & 0.82 & $(0.00)$ & 1.17 & $(0.00)$ \\
\hline Middle East *(12-16) & 0.87 & $(0.00)$ & 1.31 & $(0.00)$ \\
\hline Middle East *(17-19) & 1.06 & $(0.00)$ & 1.64 & $(0.00)$ \\
\hline Middle East *(20-25) & 0.99 & $(0.21)$ & 1.44 & $(0.00)$ \\
\hline South Asia & 1.15 & $(0.00)$ & & \\
\hline South Asia *(0-5) & 0.82 & $(0.00)$ & 0.88 & $(0.00)$ \\
\hline South Asia *(6-11) & 0.85 & $(0.00)$ & 1.03 & $(0.04)$ \\
\hline South Asia *(12-16) & 0.92 & $(0.00)$ & 1.16 & $(0.00)$ \\
\hline South Asia *(17-19) & 1.04 & $(0.00)$ & 1.36 & $(0.00)$ \\
\hline South Asia *(20-25) & 0.98 & $(0.02)$ & 1.22 & $(0.00)$ \\
\hline Rest of Asia and the Pacific & 0.89 & $(0.00)$ & & \\
\hline RoAsia/Pacific*(0-5) & 0.90 & $(0.00)$ & 0.75 & $(0.00)$ \\
\hline RoAsia/Pacific *(6-11) & 0.91 & $(0.00)$ & 0.86 & $(0.00)$ \\
\hline RoAsia/Pacific *(12-16) & 0.96 & $(0.01)$ & 0.95 & $(0.00)$ \\
\hline RoAsia/Pacific *(17-19) & 1.04 & $(0.00)$ & 1.06 & $(0.00)$ \\
\hline RoAsia/Pacific *(20-25) & 1.08 & $(0.00)$ & 1.04 & $(0.00)$ \\
\hline Africa & 1.32 & $(0.00)$ & & \\
\hline Africa $*(0-5)$ & 0.73 & $(0.00)$ & 0.90 & $(0.00)$ \\
\hline Africa * $(6-11)$ & 0.69 & $(0.00)$ & 0.96 & $(0.02)$ \\
\hline Africa * $(12-16)$ & 0.72 & $(0.00)$ & 1.05 & $(0.02)$ \\
\hline Africa *(17-19) & 0.85 & $(0.00)$ & 1.28 & $(0.00)$ \\
\hline Africa *(20-25) & 0.93 & $(0.00)$ & 1.32 & $(0.00)$ \\
\hline South America & 1.23 & $(0.00)$ & & \\
\hline South America * $(0-5)$ & 0.94 & $(0.00)$ & 1.15 & (0.00) \\
\hline South America *(6-11) & 1.06 & $(0.00)$ & 1.31 & $(0.00)$ \\
\hline South America *(12-16) & 1.10 & $(0.00)$ & 1.36 & $(0.00)$ \\
\hline South America *(17-19) & 1.14 & $(0.00)$ & 1.40 & $(0.00)$ \\
\hline South America *(20-25) & 1.08 & $(0.00))$ & 1.33 & $(0.00)$ \\
\hline $\begin{array}{l}\text { (1) The table shows the IRR from } \\
\text { controls for age, education, ma } \\
\text { (I) Displays the IRR of the varia } \\
\text { at immigration. } \\
\text { (II) Shows the cumulative effec } \\
\text { of an F-test on the significance } \\
\text { at immigration and the native }\end{array}$ & $\begin{array}{l}\text { ssion of } \\
\text { sus year } \\
\text { grouped } \\
\text { ce of bir } \\
\text { es in fer }\end{array}$ & $\begin{array}{l}\text { umber of } \\
\text { ace of re } \\
\text { of birth a } \\
\text { age at in } \\
\text { etween ir } \\
\text { igure } 5 \text {. }\end{array}$ & $\begin{array}{l}\text { in the house } \\
\text { raction of this } \\
\text { on together } v \\
\text { ts from a give }\end{array}$ & $\begin{array}{l}\text { Includes } \\
\text { grouped age } \\
\text { he p-value } \\
\text { ea and age }\end{array}$ \\
\hline
\end{tabular}


Table 6. Fertility by Age at immigration and Place of Origin ${ }^{(1)}$ (P-values in italics)

\begin{tabular}{|c|c|c|c|c|c|c|c|c|c|c|c|c|}
\hline & \multicolumn{2}{|c|}{ POB indicator } & \multicolumn{2}{|c|}{ Age 0-5 } & \multicolumn{2}{|c|}{ Age 6-11 } & \multicolumn{2}{|c|}{ Age $12-16$} & \multicolumn{2}{|c|}{ Age 17-19 } & \multicolumn{2}{|c|}{ Age $20-25$} \\
\hline & Effect & P-value & Effect & P-value & Effect & P-value & Effect & P-value & Effect & $\mathrm{P}$-value & Effect & P-value \\
\hline US & 0.91 & $(0.00)$ & 1.04 & 0.00 & 1.08 & 0.00 & 1.09 & 0.00 & 1.16 & 0.00 & 1.20 & 0.00 \\
\hline Caribbean & 1.23 & 0.00 & 0.88 & 0.00 & 1.02 & 0.29 & 1.07 & 0.00 & 0.98 & 0.38 & 0.91 & 0.00 \\
\hline Mexico & 1.37 & 0.00 & 1.24 & 0.00 & 1.21 & 0.00 & 1.13 & 0.00 & 1.32 & 0.00 & 1.01 & 0.70 \\
\hline Central Am & 1.57 & 0.00 & 0.74 & 0.00 & 0.79 & 0.00 & 0.85 & 0.00 & 0.92 & 0.03 & 0.84 & 0.00 \\
\hline South Am & 1.06 & 0.00 & 0.94 & 0.00 & 0.98 & 0.25 & 0.99 & 0.82 & 1.01 & 0.76 & 0.92 & 0.00 \\
\hline N. and C. Europe & 0.92 & 0.00 & 1.05 & 0.00 & 1.00 & 0.82 & 1.06 & 0.02 & 1.04 & 0.13 & 0.96 & 0.01 \\
\hline Eastern Europe & 0.91 & 0.00 & 0.94 & 0.01 & 0.91 & 0.00 & 0.92 & 0.00 & 0.97 & 0.17 & 0.92 & 0.00 \\
\hline UK-Ireland & 0.98 & 0.00 & 0.96 & 0.11 & 0.93 & 0.00 & 0.95 & 0.02 & 0.94 & 0.00 & 0.89 & 0.00 \\
\hline South Europe & 1.10 & 0.00 & 0.96 & 0.00 & 0.98 & 0.09 & 1.00 & 0.94 & 1.04 & 0.02 & 0.94 & 0.00 \\
\hline Middle East & 1.36 & 0.00 & 0.80 & 0.00 & 0.80 & 0.00 & 0.88 & 0.46 & 1.04 & 0.03 & 0.89 & 0.00 \\
\hline China & 0.80 & 0.00 & 0.87 & 0.00 & 0.88 & 0.00 & 0.92 & 0.03 & 1.00 & 0.94 & 0.96 & 0.00 \\
\hline North East As & 1.02 & 0.00 & 0.55 & 0.00 & 0.68 & 0.00 & 0.62 & 0.00 & 0.68 & 0.00 & 0.81 & 0.00 \\
\hline South East As & 0.97 & 0.00 & 0.72 & 0.00 & 0.86 & 0.00 & 1.01 & 0.60 & 1.03 & 0.10 & 0.99 & 0.29 \\
\hline South Asia & 1.15 & 0.00 & 0.74 & 0.00 & 0.83 & 0.00 & 0.92 & 0.34 & 1.02 & 0.21 & 0.88 & 0.00 \\
\hline North Africa & 1.21 & 0.00 & 0.87 & 0.00 & 0.87 & 0.00 & 0.88 & 0.00 & 1.03 & 0.36 & 0.92 & 0.00 \\
\hline Central Africa & 1.64 & 0.00 & 0.44 & 0.00 & 0.52 & 0.00 & 0.59 & 0.00 & 0.67 & 0.00 & 0.78 & 0.00 \\
\hline Western Africa & 1.42 & 0.00 & 0.52 & 0.00 & 0.59 & 0.00 & 0.67 & 0.14 & 0.78 & 0.00 & 1.42 & 0.00 \\
\hline South Africa & 1.10 & 0.00 & 0.76 & 0.00 & 0.73 & 0.00 & 0.75 & 0.00 & 0.80 & 0.00 & 0.83 & 0.00 \\
\hline Easter Africa & 1.46 & 0.00 & 0.47 & 0.00 & 0.52 & 0.00 & 0.76 & 0.00 & 0.77 & 0.00 & 0.77 & 0.00 \\
\hline Pacific & 0.91 & 0.00 & 1.02 & 0.59 & 1.07 & 0.06 & 1.14 & 0.00 & 1.24 & 0.00 & 1.03 & 0.20 \\
\hline
\end{tabular}

${ }^{(1)}$ The table shows the IRR from a Poisson regression of the number of children in the household. Includes controls for age, education, marital status, census year, place of residence, place of birth and indicators for age at immigration groups and their interaction with each place of birth. By default the place of birth indicator corresponds to immigrants arriving older than 25. The omitted immigrant reference category is the group of older immigrants from the US.

The total effect of fertility for an area of origin and given age at immigration is calculated as the cumulated effect of being in a particular age group in the reference area of origin, the indicator for area of origin and the interaction between these two (See footnote 23) 
Table 7. Fertility Rate by Age at Immigration and OMT relative to Native Born ${ }^{(1)}$ (P-values)

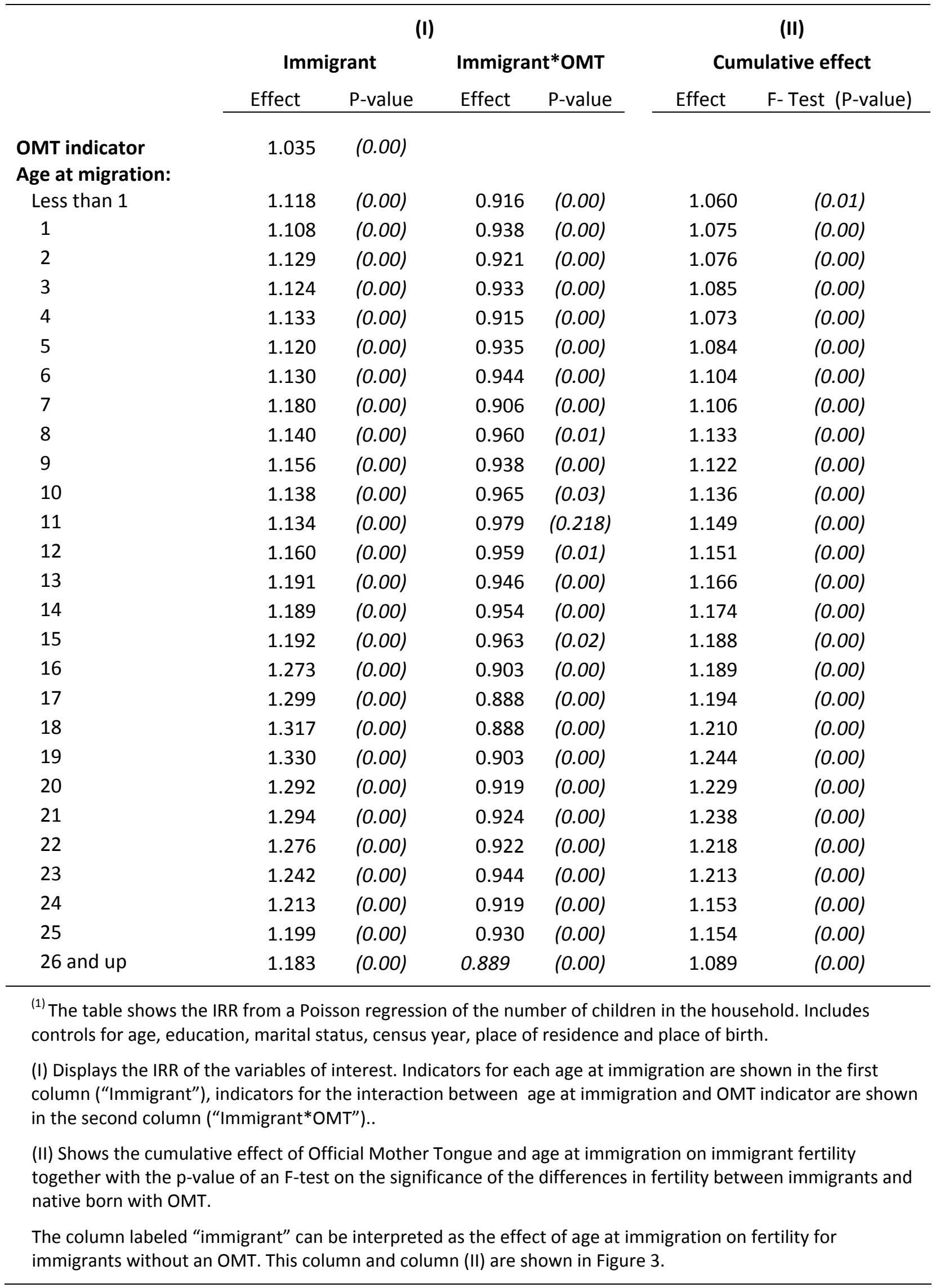


Table 8. Fertility by Age at Immigration and Education relative to Native Born ${ }^{(1)}$ (P-values)

\begin{tabular}{|c|c|c|c|c|c|c|}
\hline \multirow{3}{*}{ University } & \multicolumn{4}{|c|}{ (I) } & \multirow{2}{*}{\multicolumn{2}{|c|}{$\begin{array}{l}\text { (II) } \\
\text { Cumulative Effect }\end{array}$}} \\
\hline & \multicolumn{2}{|c|}{ Immigrant } & \multicolumn{2}{|c|}{ Immigrant*University } & & \\
\hline & Effect & $\mathrm{P}$-value & Effect & P-value & Effect & F-test (P-value) \\
\hline $\begin{array}{l}\text { University } \\
\text { indicator }\end{array}$ & 0.77 & $(0.00)$ & & & & \\
\hline \multicolumn{7}{|c|}{ Age at migration: } \\
\hline Less than 1 & 1.05 & $(0.00)$ & 0.91 & $(0.00)$ & 0.736 & $(0.02)$ \\
\hline 1 & 1.05 & $(0.00)$ & 0.93 & $(0.00)$ & 0.747 & (0.16) \\
\hline 2 & 1.05 & $(0.00)$ & 0.97 & $(0.07)$ & 0.779 & $(0.32)$ \\
\hline 3 & 1.06 & $(0.00)$ & 0.93 & $(0.00)$ & 0.757 & (0.49) \\
\hline 4 & 1.07 & $(0.00)$ & 0.91 & $(0.00)$ & 0.744 & (0.09) \\
\hline 5 & 1.07 & $(0.00)$ & 0.90 & $(0.00)$ & 0.737 & $(0.02)$ \\
\hline 6 & 1.08 & $(0.00)$ & 0.91 & $(0.00)$ & 0.751 & $(0.25)$ \\
\hline 7 & 1.11 & $(0.00)$ & 0.90 & $(0.00)$ & 0.765 & (0.93) \\
\hline 8 & 1.11 & $(0.00)$ & 0.86 & $(0.00)$ & 0.733 & $(0.02)$ \\
\hline 9 & 1.11 & $(0.00)$ & 0.86 & $(0.00)$ & 0.733 & $(0.02)$ \\
\hline 10 & 1.09 & $(0.00)$ & 0.90 & $(0.00)$ & 0.758 & $(0.60)$ \\
\hline 11 & 1.10 & $(0.00)$ & 0.89 & $(0.00)$ & 0.750 & $(0.26)$ \\
\hline 12 & 1.12 & $(0.00)$ & 0.88 & $(0.00)$ & 0.753 & (0.39) \\
\hline 13 & 1.14 & $(0.00)$ & 0.87 & $(0.00)$ & 0.762 & $(0.78)$ \\
\hline 14 & 1.15 & $(0.00)$ & 0.84 & $(0.00)$ & 0.740 & (0.07) \\
\hline 15 & 1.15 & $(0.00)$ & 0.83 & $(0.00)$ & 0.737 & (0.05) \\
\hline 16 & 1.21 & $(0.00)$ & 0.80 & $(0.00)$ & 0.742 & (0.11) \\
\hline 17 & 1.22 & $(0.00)$ & 0.84 & $(0.00)$ & 0.782 & $(0.27)$ \\
\hline 18 & 1.23 & $(0.00)$ & 0.85 & $(0.00)$ & 0.801 & (0.01) \\
\hline 19 & 1.24 & $(0.00)$ & 0.91 & $(0.00)$ & 0.862 & $(0.00)$ \\
\hline 20 & 1.20 & $(0.00)$ & 0.98 & (0.14) & 0.901 & $(0.00)$ \\
\hline 21 & 1.20 & $(0.00)$ & 1.02 & $(0.17)$ & 0.930 & $(0.00)$ \\
\hline 22 & 1.17 & $(0.00)$ & 1.03 & $(0.01)$ & 0.927 & $(0.00)$ \\
\hline 23 & 1.15 & $(0.00)$ & 1.03 & $(0.01)$ & 0.907 & $(0.00)$ \\
\hline 24 & 1.12 & $(0.00)$ & 0.99 & $(0.21)$ & 0.848 & $(0.00)$ \\
\hline 25 & 1.12 & $(0.00)$ & 0.96 & $(0.00)$ & 0.827 & $(0.00)$ \\
\hline 26 and up & 1.08 & $(0.00)$ & 0.99 & (0.04) & 0.830 & $(0.00)$ \\
\hline \multicolumn{7}{|c|}{$\begin{array}{l}\text { (1) The table shows the IRR from a Poisson regression of the number of children in the household. Includes } \\
\text { controls for age, education, marital status, census year, place of residence and place of birth. }\end{array}$} \\
\hline \multicolumn{7}{|c|}{$\begin{array}{l}\text { (I) Displays the IRR of the variables of interest. The IRR for each age at immigration is shown in the first column } \\
\text { ("Immigrant"), the IRR for the interaction between age at immigration and university indicator is shown in the } \\
\text { second column ("Immigrant*University"). }\end{array}$} \\
\hline \multicolumn{7}{|c|}{$\begin{array}{l}\text { (II) Shows the cumulative effect of university education and age at immigration on immigrant fertility together } \\
\text { with the } p \text {-value of an F-test on the significance of the differences in fertility between immigrants and native } \\
\text { born with university education. }\end{array}$} \\
\hline
\end{tabular}




\section{FIGURE 1}

Distribution of Immigrants by Age at Immigration, Census 1991-2006

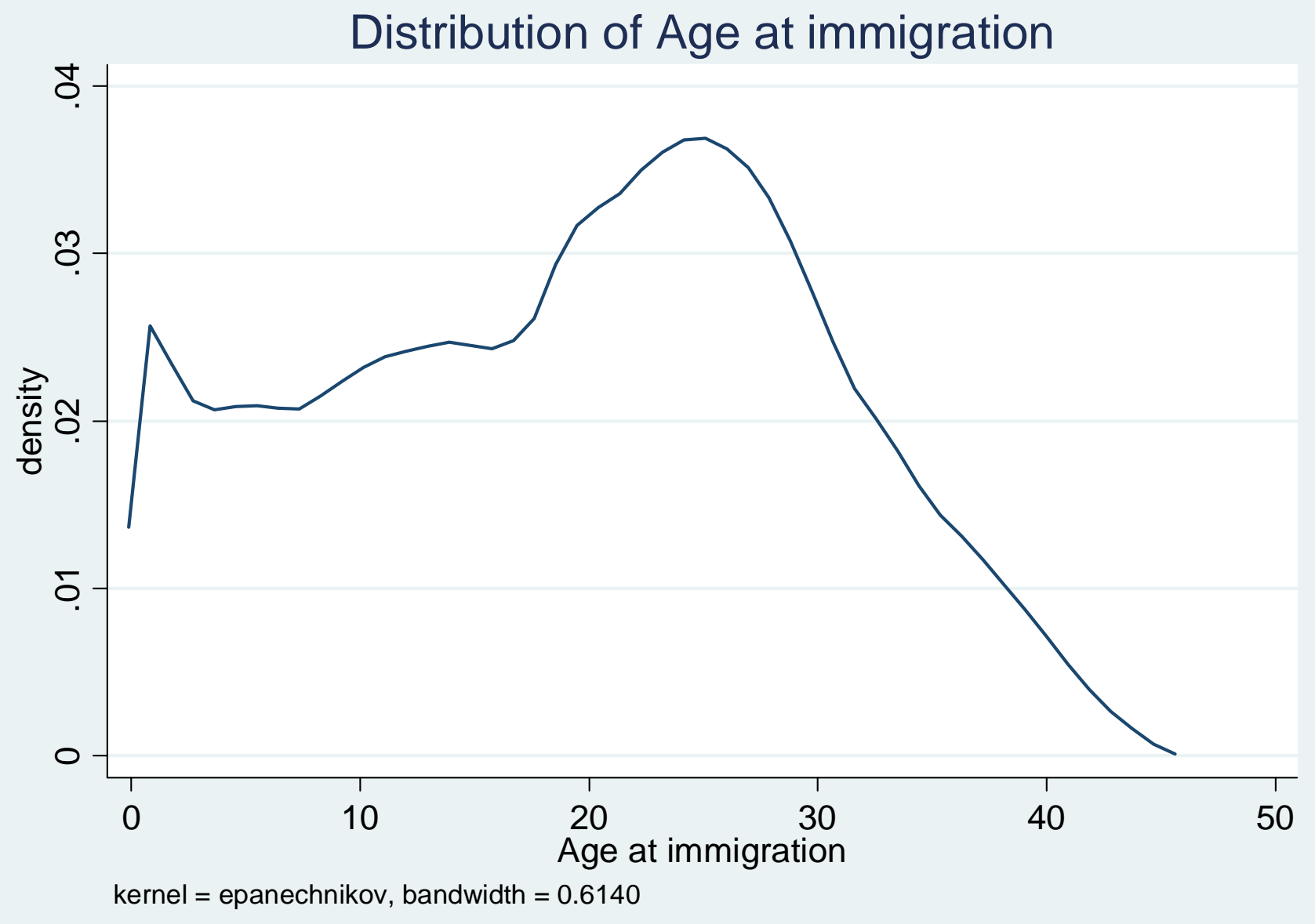


Figure 2: Fertility by Age at Migration relative to Native Born.

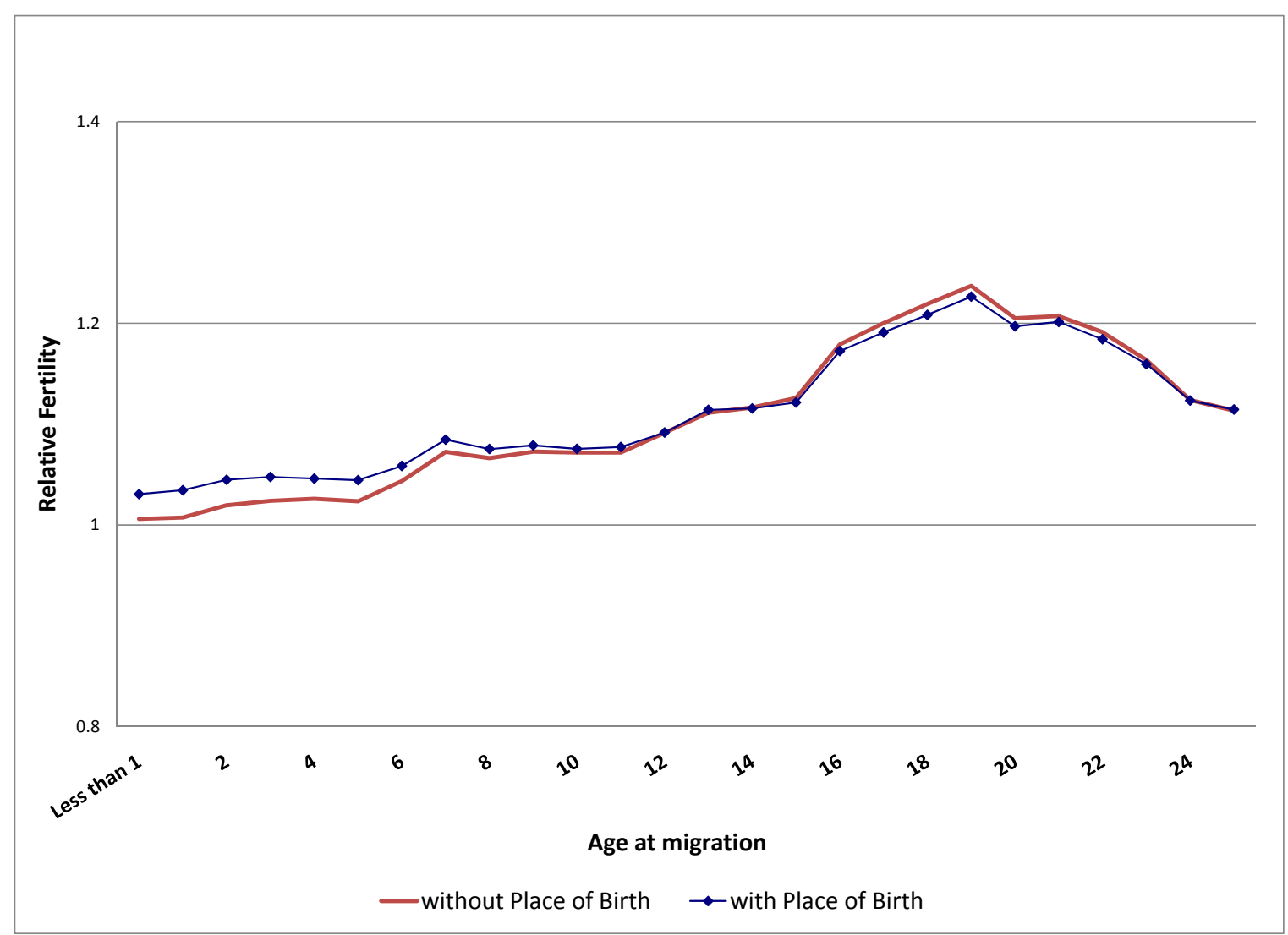

Note: Estimated fertility relative to Canadians from Poisson regressions in Table 4. Controls for age, education, marital status, location of residence and census year are included. In the model with place of birth, the US is the reference group shown in graph. 
Figure 3: Fertility by Grouped Age at Migration and Place of Birth

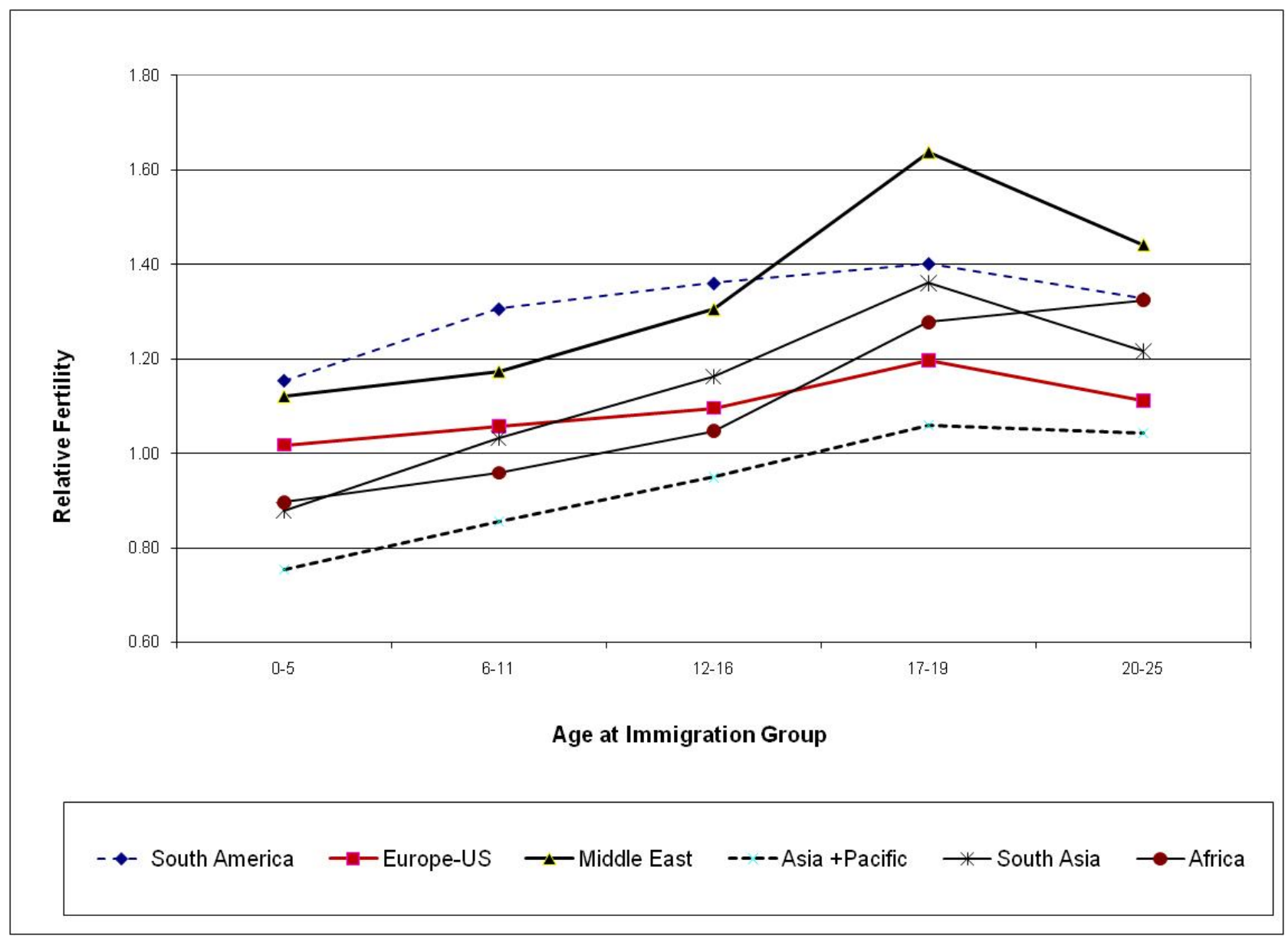

Note: Estimated fertility relative to Canadians from Poisson regression in Table 5. Controls for age, education, marital status, location of residence, census year and place of birth are included. 
Figure 4: Fertility by Age at Migration and Official Mother Tongue (OMT)

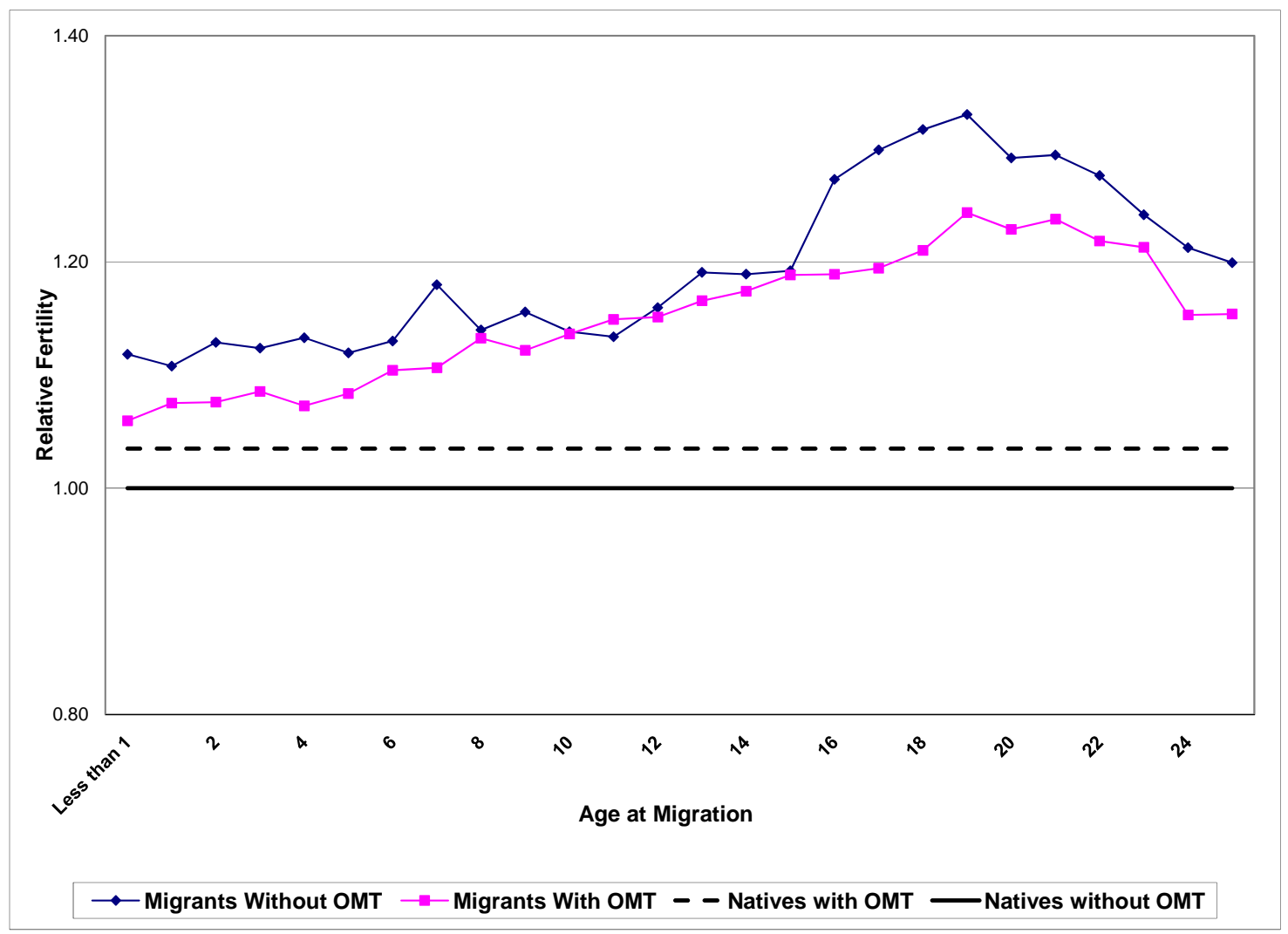

Note: Estimated fertility relative to Canadians with no OMT from Poisson regression in Table 7. Controls for age, education, marital status, location of residence, census year and place of birth (re: USA) are included. 
Figure 5: Fertility by Age at Migration and Educational Attainment

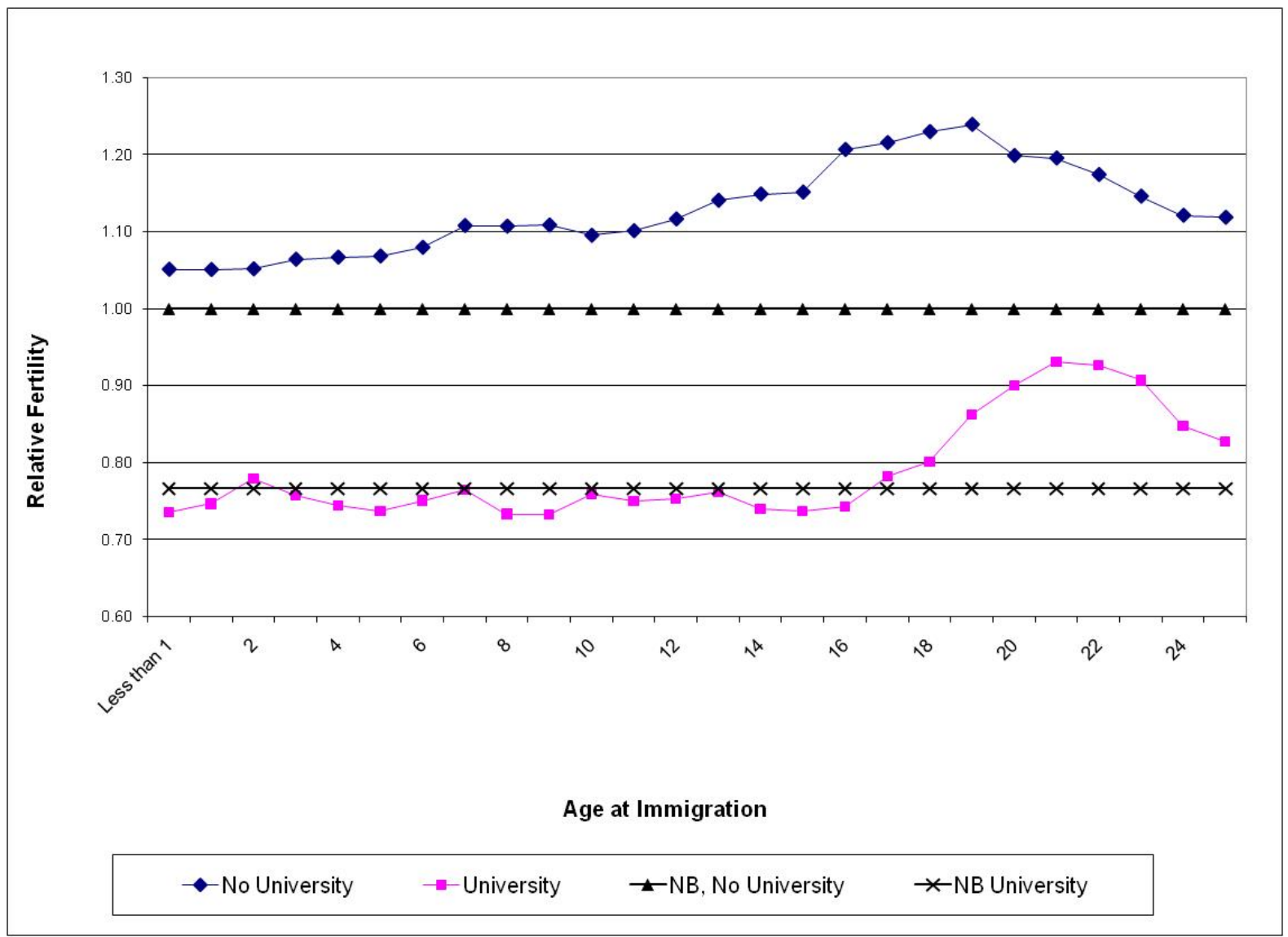

Note: Estimated fertility relative to Canadians with no university education from Poison regression in Table 8. Controls for age, education, marital status, location of residence, census year and place of birth are included. 
Table A1. Fertility Rates by Area of Origin

I. Basic model

Relative fertility rate

\begin{tabular}{|c|c|}
\hline Native born & -- \\
\hline \multicolumn{2}{|l|}{ Immigrant } \\
\hline US & -- \\
\hline Caribbean & $1.15^{\star \star}$ \\
\hline Mexico & $1.37^{\star *}$ \\
\hline Central America & $1.35^{\star \star}$ \\
\hline South America & 0.99 \\
\hline North and Central Europe & $0.94^{\star *}$ \\
\hline Eastern Europe & $0.88^{\star \star}$ \\
\hline UK / Ireland & $0.92^{\star \star}$ \\
\hline Southern Europe & $1.02^{\star \star}$ \\
\hline Middle East & $1.25^{\star *}$ \\
\hline China & $0.76^{\star \star}$ \\
\hline North Eastern Asia & $0.92^{\star *}$ \\
\hline South East Asia & $0.91^{\star *}$ \\
\hline Southern Asia & $1.06^{\star \star}$ \\
\hline North Africa & $1.17^{\star \star}$ \\
\hline Central Africa & $1.33^{\star *}$ \\
\hline West Africa & $1.27^{\star \star}$ \\
\hline Southern Africa & $0.97^{\star *}$ \\
\hline Eastern Africa & $1.16^{\star \star}$ \\
\hline Pacific & $0.95^{\star \star}$ \\
\hline Observations & $1,835,326$ \\
\hline
\end{tabular}

The table shows the effect of place of birth on fertility from the basic model shown in table 4, column II. The Poisson regression also includes controls for age, education, marital status, census year, place of residence and a full set of age at immigration indicators.

$\left.{ }^{\star \star \star \star}\right)$ indicates significant at $1 \%,\left({ }^{\star \star}\right)$ indicates significance at 5 percent. 


\section{TABLE 1B. Classification of Countries by Region of Origin}

Caribbean: Cuba, Dominican Republic, Haiti, Puerto Rico, Jamaica, Trinidad and Tobago, Guadeloupe, Martinique, Bahamas, Barbados, Netherlands Antilles, Saint Lucia, Saint Vincent and the Grenadines Virgin Islands, US Grenada, Antigua and Barbuda, Dominica, Cayman Islands, Aruba, Anguilla, Bermuda, Montserrat, Saint Kitts and Nevis Turks and Caicos Islands, British Virgin Islands

Central America: Belize, Costa Rica, El Salvador, Guatemala, Honduras, Nicaragua, Panama

South America: Argentina, Bolivia, Brazil, Chile, Colombia, Ecuador, Falkland Islands (Malvinas), French Guiana, Guyana, Paraguay, Peru, Suriname, Uruguay, Venezuela.

Northern and Central Europe: Greenland, Denmark, Finland, Iceland, Norway, Sweden, Austria, Belgium, Germany, Liechtenstein, Luxembourg, Monaco, Netherlands, Switzerland, France..

Eastern Europe: Bulgaria, Czech Republic, Slovakia, Czechoslovakia, n.i.e., Hungary, Poland, Romania, Estonia, Latvia, Lithuania, Belarus, Moldova, Republic of Russian, Albania Federation, Ukraine, USSR., n.i.e., Bosnia and Herzegovina, Croatia, Slovenia, Yugoslavia

Southern Europe: Andorra, Gibraltar ,Greece, Italy, Malta, Portugal, San Marino, Spain, Vatican City State, Macedonia

UK Ireland: Ireland, Republic of (Eire) United Kingdom

Middle East: Afghanistan, Cyprus, Iran, Turkey, Armenia, Azerbaijan, Georgia, Kazakstan, Kyrgyzstan, Tajikistan, Turkmenistan, Uzbekistan, Bahrain, Iraq, Israel, Jordan, Kuwait, Lebanon, Oman, Qatar, Saudi Arabia, Syria, United Arab Emirates, Yemen, Palestine/West Bank/Gaza Strip

China: People’s Republic of China, Hong Kong, Macao, Mongolia

North Eastern Asia: Japan, Korea, North Korea, South Taiwan

South East Asia: Cambodia, Indonesia, Laos, Malaysia, Myanmar, Singapore, Thailand, Vietnam

Southern Asia: Philippines, Bangladesh, Bhutan, India, Maldives, Nepal, Pakistan, Sri Lanka

North Africa: Algeria, Egypt, Libya, Morocco, Tunisia, Sudan, Western Sahara

Central Africa: Cameroon, Central African Republic, Chad, Congo, Equatorial Guinea, Gabon, $\underline{\text { Sao Tome and }}$ Principe, Zambia, Zaire

West Africa: Benin, Burkina Faso, Côte d'Ivoire, Cape Verde, The Gambia, Ghana, Guinea, Guinea-Bissau, Liberia, Mali, Mauritania, Niger, Nigeria, Senegal, Sierra Leone, Togo

Southern Africa: Botswana, Lesotho, Namibia, Republic of South Africa, Swaziland

Eastern Africa: Eritrea, Uganda, Sudan, Kenya, Tanzania, Rwanda, Burundi, Somalia, Djibouti, Ethiopia, Comoros, Madagascar, Malawi, Mauritius, Mayotte, Mozambique, Reunion, Seychelles, Zimbawe

Pacific: American Samoa, Australia, Cook Islands, Fiji, Polynesia, New Caledonia, New Zealand 